\title{
Partition by exhaustification: Comments on Dayal $1996^{1}$
}

Danny FOX - Massachusetts Institute of Technology

\begin{abstract}
In this paper I argue for a new constraint on questions, namely that a question denotation (a set of propositions) must map to a partition of a Stalnakerian Context-Set by point-wise exhaustification (point-wise application of the function Exh). The presupposition that Dayal attributes to an Answer operator follows from this constraint, if we assume a fairly standard definition of Exh (Krifka, 1995). But the constraint is more restrictive thereby deriving the sensitivity of higher order quantification to negative islands (Spector, 2008). Moreover, when combined with recent proposals about the nature of Exh - designed primarily to account for the conjunctive interpretation of disjunction (e.g. Bar-Lev and Fox, 2017) - Dayal's presupposition follows only in certain environments. This observation allows for an account of the "mention-some" interpretation of questions that makes specific distributional predictions.
\end{abstract}

Keywords: exhaustivity, Free Choice, maximality, higher-order quantification, mentionsome, negative-islands, partition, scalar implicatures, uniqueness.

\section{Introduction}

According to Dayal (1996), a question denotation is a set of propositions (as in Hamblin, 1973) and an interrogative construction presupposes that one member of the set is true and entails all other true members (i.e. is a most informative true member). This maximality presupposition has been defended in two different ways. Frist, Dayal showed how it accounts for various inferential patterns: existence inference for plural constituent questions (which girls are here?) and uniqueness for their singular counterparts (which girl is here?). Second, later literature has pointed out that the maximality presupposition can also account for various constraints on question formation, most clearly for negative islands. ${ }^{2}$

I will begin this paper with a new perspective on Dayal's proposal. Under this perspective, the maximality presupposition is not taken as primitive but is derived instead from the demand that a complete answer to a question be identifiable by exhaustification. More specifically, I will propose that any possible complete answer to a question (every cell in the partition the question induces) must be derivable by the exhaustification of a member of the question denotation. This perspective invites two modifications in the presupposition, which, in turn, overcome two empirical challenges, one coming from the "mention-some" interpretation of questions (MS) and the other from a new form of extraction sensitive to negative islands (Spector, 2008). MS can be explained when the demand of cell-identification is combined with recent proposals in the theory of exhaustification. The sensitivity to negative islands is explained by strengthening cell-identification, demanding that

\footnotetext{
${ }^{1}$ This paper is based on earlier presentations at MIT (2010, 2013), ZAS (2015) and UCM (2016). Thanks in particular, to Meredith Alongi, Moysh Bar-Lev, David Beaver, Sigrid Beck, Seth Cable, Gennaro Chierchia, Luka Crnič, B. R. George, Patrick Grosz, Martin Hackl, Irene Heim, Aron Hirsch, Roni Katzir, Manuel Križ, Floris Roelofsen, Roger Schwarzschild, Benjamin Spector, Wataru Uegaki, and Yimei Xiang.

2 See Fox and Hackl, 2006; Abrusán and Spector, 2011; Abrusán, 2007, 2014. For other islands that might have a semantic account see Abrusán, 2007, 2014; Oshima, 2007; and Schwarz and Simonenko, 2016.
} 
exhaustification yield a mapping from question denotation onto the partition. The resulting picture can then be redrawn (as pointed out to me by Roger Schwarzschild). Specifically, we can dispense with the standard definition of the partition-induced-by-a-question and simply demand that (point-wise) exhaustification partition the context-set.

\subsection{The duality of questions - an arithmetic challenge}

When is a proposition relevant to a question (or when is it about the topic that the question introduces)? When is it informative relative to the question? When does it provide a complete or a partial answer? These issues, which are central for various areas of pragmatics, can be addressed straightforwardly when we think of a question as a partition of a space of possibilities - Logical Space, or the Stalnakerian Context-Set. Entertaining a question involves a concern with locating oneself in a space of possibilities, where certain distinctions matter and others don't. A partition is useful for describing such a concern. What matters given a partition (what is relevant) is what cell you're in. So a proposition that distinguishes between cell members (true of some, false of others) will be irrelevant. If a proposition eliminates a cell, it will be informative (i.e. will provide a partial answer to the question), and if it eliminates all but one cell, it will be maximally informative, thus providing a complete answer. $^{3}$

(1) Question Pragmatics (Hamblin, Groenendijk and Stokhof, Lewis, etc.)

A Question characterizes a topic of conversation and as such tells us what is relevant, informative, orthogonal, etc.

$\rightarrow \quad$ Question as Partition (of a space of possibilities)

But since Heim (1994) there has been growing evidence that questions do not denote partitions. The arguments are by now quite involved (besides Heim, see also Guerzoni, 2003; Guerzoni and Sharvit, 2007, 2014; Klinedinst and Rothschild, 2011; Cremers and Chemla, 2016; Spector and Egré, 2015; Xiang, 2016). Heim's original case can be illustrated through a comparison of certain questions that need to be associated with the same partition but, nevertheless, differ in their semantic properties. For example, the question who (among Mary, Sue and Jane) is here? has a different denotation from its negative counterpart: who (among Mary, Sue and Jane) is not here? This difference can be seen when looking at the different results obtained when embedding the two questions under the verb surprise: John is surprised by who is here means something different from John is surprised by who is not here. ${ }^{4}$ At the same time, the two questions determine the same partition, as no proposition can be relevant or informative relative to one of these questions without bearing the same relationship to the other. ${ }^{5}$

\footnotetext{
${ }^{3}$ For additional useful notions that can be elucidated with partitions, see Groenendijk and Stokhof, 1984; Lewis, 1987 and much subsequent work.

${ }^{4}$ Heim concludes that the propositional argument of surprise must be the weakly exhaustive answer to the question. But Spector and Egré (2015) provide evidence for a more nuanced conclusion, which might be relevant later on (see note 39 ).

${ }^{5}$ The argument can be appreciated most clearly when focusing on the de re reading of questions. On relevant complications that come from the de-dicto interpretations, see George, 2011. Throughout this paper I will be focusing on the de re interpretation.
} 
So, as Heim pointed out, a partition does not provide enough information to explain the semantic contribution of a question to the meaning of an indicative sentence in which it is embedded. A popular response to this observation - the one advocated by Heim - is that questions denote sets of propositions (so called, Hamblin sets). These sets are not always mutually exclusive, and hence do not necessarily partition a set of possibilities. ${ }^{6}$

(2) Question Semantics (Heim, Klinedinst and Rothschild, Cremers and Chemla, etc.)

Questions show an asymmetry between positive and negative information. Therefore, questions cannot denote partitions.

$\rightarrow \quad$ Question as Set of Propositions (not necessarily mutually exclusive)

Our questions who is here? and who is not here?, in particular, denote two different sets of mutually compatible propositions $(\{p: \exists x \in A p=\lambda w$. $x$ is here in $w\}$ and $\{p: \exists x \in A p=\lambda w . x$ is not here in $\mathrm{w}\}$ ). And the difference between these two sets suffices to explain the different consequences that arise when the two questions are embedded as arguments of surprise. ${ }^{7}$

But since partitions are necessary for understanding question pragmatics (the function of a question in thought and communication), we need to derive them from question denotations. And this can be done in a very simple way (as pointed out by many). Specifically, if we have a set of propositions, Q, we can partition Logical Space to sets of possibilities that agree with each other on the truth-value of members of Q.

(3) The partition of Logical Space induced by $Q$, Partition $(\mathrm{Q})$ - henceforth the Logical Partition, is the set of equivalence classes of $W$ under the relation

$$
w \sim w^{\prime} \text { iff } \forall \mathrm{p} \in \mathrm{Q}\left[\mathrm{p}(\mathrm{w})=\mathrm{p}\left(\mathrm{w}^{\prime}\right)\right]
$$

I'll illustrate with a very simple case. Suppose we want to know which of two logically independent propositions, $\mathrm{p}$ and $\mathrm{q}$, are true. This can be restated as a desire to determine the truth-value of each of the two propositions, i.e., to locate ourselves in the partition $\mathrm{P}=\{\neg \mathrm{p} \& \neg \mathrm{q}, \mathrm{p} \& \neg \mathrm{q}, \mathrm{q} \& \neg \mathrm{p}, \mathrm{p} \& \mathrm{q}\}$. But if we want to express this desire, we might do so using a natural language expression with denotation $\mathrm{Q}=\{\mathrm{p}, \mathrm{q}\}$. Although this denotation is not a partition, the desired partition can be retrieved from it $\left(\mathrm{P}=\operatorname{Partition}_{\mathrm{L}}(\mathrm{Q})\right)$.

$$
\begin{aligned}
& \mathrm{Q}=\{\mathrm{p}, \mathrm{q}\} \text { where } \mathrm{p} \text { and } \mathrm{q} \text { are logically independent } \\
& \qquad \operatorname{Partition}_{\mathrm{L}}(\mathrm{Q})=\{\neg \mathrm{p} \& \neg \mathrm{q}, \mathrm{p} \& \neg \mathrm{q}, \mathrm{q} \& \neg \mathrm{p}, \mathrm{p} \& \mathrm{q}\}
\end{aligned}
$$

This can serve to clarify the relationship between the two natural language questions mentioned above: the two questions (who is here? and who is not here?) denote two different sets of propositions ( $\{$ that $\mathrm{a}$ is here, that $\mathrm{b}$ is here,...\} and \{that $\mathrm{a}$ is not here, that $\mathrm{b}$ is not here,...\}); yet, by (3), the two sets induce the same partition.

\footnotetext{
${ }^{6}$ Hamblin, 1973 as apposed to Hamblin, 1958. See Hagstrom, 2003, for a survey.

${ }^{7}$ For competing proposals about what it means to be surprised by Q, see George 2011 (3.2), Heim, 1994; Lahiri, 2002, and Spector and Egré, 2015.
} 
So there are two different and indispensible notions of a question ((1) and (2)) - question duality. But there is a very simple way to connect them. The notion in (2) is the one delivered by grammar, and the notion in (1), necessary for pragmatics, is retrieved by the function in (3). All of this is simple enough. But now I would like to discuss a rather mundane observation about the typical relationship between questions and answers and suggest a way to think about it that leads to a problem. The problem, I will argue, is useful in understanding empirical constraints on questions. Specifically, I will argue that questions are unacceptable whenever this problem cannot be resolved.

Typically, a question with denotation $\mathrm{Q}$ is answered by a sentence denoting a proposition in Q. Yet the answer manages to convey a cell in the partition, by its exhaustive interpretation:

(5) Question: Who (among Jane, Mary and Sue) is here.

Answer: Mary is here.

(exhaustive interpretation: Mary is here and Sue and Jane aren't.)

(6) Observation about Answers:

A question, with denotation $\mathrm{Q}$, is typically answered by a proposition $\mathrm{p}$, such that $\mathrm{p} \in \mathrm{Q}$, hence is not, itself, a cell in $\operatorname{Partition}_{\mathrm{L}}(\mathrm{Q})$. Still $\mathrm{p}$ manages (by exhaustification) to identify a cell.

Imagine that we turn this observation into a principle:

\section{(7) Question Answer Matching: ${ }^{8}$}

A question whose denotation, $\mathrm{Q}$, is a set of propositions must be answered by a single sentence whose basic denotation (prior to exhaustification) is a member of Q.

This principle, now, leads to an automatic arithmetic problem. Many questions will be unanswerable in many situations. For example, when $\mathrm{Q}$ has $\mathrm{n}$ logically independent proposition, $\operatorname{Partition}_{\mathrm{L}}(\mathrm{Q})$ will have $2^{\mathrm{n}}$ members:

(8) Question Answer Duality - an Arithmetic Problem:

There will be cases in which cells in $\operatorname{Partition}_{\mathrm{L}}(\mathrm{Q})$ will not be identifiable by a member of Q (based on simple numerical considerations).

Illustration: $I n(4), Q=\{p, q\}$ contains 2 propositions yet Partition $_{L}(\mathrm{Q})$ contains 4 :

$\mathrm{p}$, by exhaustification, is strengthened to $\mathrm{p} \& \neg \mathrm{q}$; $\mathrm{q}$ is strengthened to $\mathrm{q} \& \neg \mathrm{p}$

The cells $\neg p \& \neg q, p \& q$ cannot be identified.

\subsection{Dayal's presupposition as a solution to an arithmetic challenge}

As mentioned, Dayal argues that an interrogative construction presupposes that one member of the question denotation is true and entails all other true members (i.e. is a most informative

\footnotetext{
${ }^{8}$ This condition is close to Rooth's (1992) demand that the focus value of answer to a question be a super-set of the question denotation. However, Rooth's principle allows a question to be answered by a sequence of sentences each of which satisfies his condition independently. For possible arguments that the condition needs to be satisfied by a single sentence, see Bade, 2016; Aravind and Hackl, 2017.
} 
true member). This maximality presupposition is encoded in the meaning of an obligatory lexical item - Dayal's answer operator, $A n s_{D}$. Every question must merge with $A n s_{D}$, yielding an interrogative construction that carries a maximality presupposition.

(9) Dayal (1996):

a. $\quad \operatorname{Ans}_{\mathrm{D}}(\mathrm{Q})=\lambda \mathrm{w}: \exists \mathrm{p} \in \mathrm{Q}\left[\mathrm{p}=\operatorname{Max}_{\text {inf }}(\mathrm{Q}, \mathrm{w})\right] . \operatorname{Max}_{\text {inf }}(\mathrm{Q}, \mathrm{w})$

b. $\operatorname{Max}_{\text {inf }}(\mathrm{Q}, \mathrm{w})=\mathrm{p}$ iff $\mathrm{w} \in \mathrm{p} \& \forall \mathrm{q} \in \mathrm{Q}[\mathrm{w} \in \mathrm{q} \rightarrow \mathrm{p} \subseteq \mathrm{q}]$.

If the presupposition of $A n s_{D}$ is met, the arithmetic problem mentioned in (8) disappears. Suppose that A is a Stalnakerian Context-Set (a set of worlds that satisfy what is presupposed in a conversational context). When an interrogative construction is used, the presupposition of $A n s_{D}$ will be met (by Stalnaker's bridge principle), and every world in A will satisfy a unique proposition of the form $\lambda w$. [ $\left.\operatorname{Max}_{\text {inf }}(Q, w)=p\right]$, for some $p \in Q$. Moreover, every cell in the partition of A (as defined in (10)) will be identifiable (through exhaustification) by specifying the unique proposition of this form that satisfies the worlds in this cell.

(10) The partition of context-set $A$ induced by $Q$, Partition $(\mathrm{Q}, \mathrm{A})$ - henceforth the Contextual Partition, is the set of equivalence classes of A under the relation: $w \sim w^{\prime}$ iff $\forall \mathrm{p} \in \mathrm{Q}\left[\mathrm{p}(\mathrm{w})=\mathrm{p}\left(\mathrm{w}^{\prime}\right)\right]$

(11) If Dayal's presupposition is met, $\operatorname{Partition}_{\mathrm{C}}(\mathrm{Q}, \mathrm{A})$ can be re-written as $\left\{[\operatorname{Exh}(Q, p)]_{\mathrm{A}}: \mathrm{p} \in \mathrm{Q}\right\}$, where $\operatorname{Exh}(Q, p)=\lambda \mathrm{w} . \mathrm{w} \in \mathrm{p} \& \forall \mathrm{q} \in \mathrm{Q}[\mathrm{w} \in \mathrm{q} \rightarrow \mathrm{p} \subseteq \mathrm{q}]$ $=\lambda \mathrm{w} . \operatorname{Max}_{\text {inf }}(\mathrm{Q}, \mathrm{w})=\mathrm{p}$. and $\phi_{\mathrm{A}}$ is the portion of $\mathrm{A}$ that satisfies $\phi$, i.e., $\mathrm{A} \cap \phi$.

(12) Simple Solution to the problem in (8): If $A$ is a context set that satisfies the presupposition of $\mathrm{Ans}_{\mathrm{D}}(\mathrm{Q})$, then every cell in $\operatorname{Partition}_{\mathrm{C}}(\mathrm{Q}, \mathrm{A})$ is identifiable by a member of Q:

$$
\forall C \in \operatorname{Partition}_{\mathrm{C}}(\mathrm{Q}, \mathrm{A}) \exists \mathrm{p} \in \mathrm{Q}\left([\operatorname{Exh}(Q, p)]_{\mathrm{A}}=\mathrm{C}\right) .
$$

\section{Illustration:}

$\mathrm{Q}=\{\mathrm{p}, \mathrm{q}\}$ where $\mathrm{p}$ and $\mathrm{q}$ are logically independent,

$\mathrm{A}$ is a context set in which the presupposition of $A n s_{D}$ is met

$$
\operatorname{Partition}_{\mathrm{C}}(\mathrm{Q}, \mathrm{A}) \subseteq\left\{[\mathrm{p} \& \neg \mathrm{q}]_{\mathrm{A}},[\mathrm{q} \& \neg \mathrm{p}]_{\mathrm{A}}\right\}=\left\{[\operatorname{Exh}(Q, p)]_{\mathrm{A}},[\operatorname{Exh}(Q, q)]_{\mathrm{A}}\right\}
$$

So here is where we are. We have seen an arithmetic problem that arises when we focus on the Logical Partion of Q (given in (3)). Specifically, we have seen that there will be many cases where we won't be able to identify cells in that partition by a proposition in the question's denotation. But we have also seen that things change when we move to talk about the Contextual Partition (given in (10)). If Dayal's presupposition is met, there will never be more cells in that partition than propositions in the question's denotation. Moreover, every cell in the partition will be derived when the context-set is updated by the exhaustification of a proposition in the question denotation (as we saw in (12)).

\footnotetext{
${ }^{9}$ Note that although an answer to a question must identify a cell by exhaustification, the answer to a question according to Dayal is not the cell itself, but rather the proposition that would identify the cell if exhaustified,
} 


\subsection{Evidence for Dayal's Solution}

As mentioned at the very beginning, two pieces of evidence have been presented in favor of Dayal's presupposition. One, brought up by Dayal, comes from the inferences we draw from admissible questions and the other, presented in later work, comes from patterns of acceptability, in particular negative islands.

\subsubsection{Inferences of admissible questions}

Consider the interrogative constructions in (13). Dayal's presupposition (together with certain assumptions about the meaning of the whP's restrictor) derive (i) an existence presupposition for all the constructions in (13) (that at least one of a b and c came to the party) and (ii) a uniqueness presupposition for (13)a (that at most one of the three came). And these presuppositions are supported in that they account for inferences that speakers draw from these constructions. ${ }^{10}$

(13) a. Which girl (among a, b and c) came to the party?

b. Who (among a, b and c) came to the party?

c. Which girls (among $\mathrm{a}, \mathrm{b}$ and $\mathrm{c}$ ) came to the party?

To see how the presuppositions follow, consider first (13)a. The Hamblin set associated with the question is provided in (14). Since this set contains three logically independent propositions (corresponding to the three girls), it can have a maximally informative true member, only if exactly one of the three propositions is true.

(14) $\mathrm{Q}=\left\{\mathrm{p}_{\mathrm{a}}, \mathrm{p}_{\mathrm{b}}, \mathrm{p}_{\mathrm{c}}\right\} \quad$ (*three logically independent propositions corresponding to the three girls*)

Presupposition: exactly one proposition among the three is true

(Eliminates five cells in the Logical Partition.)

$$
\begin{aligned}
& \operatorname{Partition~}_{\mathrm{C}}(\mathrm{Q}, \mathrm{A}) \subseteq \subseteq^{11} \quad\left\{\left[\mathrm{p}_{\mathrm{a}} \& \neg \mathrm{p}_{\mathrm{b}} \& \neg \mathrm{p}_{\mathrm{c}}\right]_{\mathrm{A}}, \quad\left[\mathrm{p}_{\mathrm{b}} \& \neg \mathrm{p}_{\mathrm{a}} \& \neg \mathrm{p}_{\mathrm{c}}\right]_{\mathrm{A}}, \quad\left[\mathrm{p}_{\mathrm{c}} \& \neg \mathrm{p}_{\mathrm{a}} \& \neg \mathrm{p}_{\mathrm{b}}\right]_{\mathrm{A}}\right\} \\
& {\left[=\left\{\left[\operatorname{Exh}\left(Q, p_{\mathrm{a}}\right)\right]_{\mathrm{A}}, \quad\left[\operatorname{Exh}\left(Q, p_{\mathrm{b}}\right)\right]_{\mathrm{A}}, \quad\left[\operatorname{Exh}\left(Q, p_{\mathrm{c}}\right)\right]_{\mathrm{A}}\right\}\right]}
\end{aligned}
$$

Consider next (13)b,c, and their Hamblin denotation, Q, in (15). Q contains seven propositions corresponding to pluralities of the three girls. If there is no true proposition in the set, there is, of course, no maximally informative true member, hence an existence presupposition is derived. However, nothing is predicted beyond this existence presupposition. If one of the propositions is true, the set is guaranteed to have a maximally

otherwise we would not have an argument that questions do not denote partitions directly. This duality will continue to hold in the proposal I will be making, but see note 39.

${ }^{10}$ The existence inference is weaker in (13)b than in the other sentences. To account for this, we might assume that restrictor of the whP, who, can be true of what Bylinina and Nouwen (to appear) call the zero individual.

11 Equality (rather then the subset relation) does not hold for every context-set A that satisfies Dayal's presupposition. If A satisfies Dayal's presupposition, every w $\in A$ is guaranteed to satisfy one of the exhaustified propositions: $\operatorname{Exh}\left(Q, p_{\mathrm{a}}\right)$ or $\operatorname{Exh}\left(Q, p_{\mathrm{b}}\right)$ or $\operatorname{Exh}\left(Q, p_{\mathrm{c}}\right)$. Subsequently, Partition ${ }_{\mathrm{C}}(\mathrm{Q}, \mathrm{A})$ is guaranteed to be a subset of $\left\{\left[\operatorname{Exh}\left(Q, p_{\mathrm{a}}\right)\right]_{\mathrm{A}},\left[\operatorname{Exh}\left(Q, p_{\mathrm{b}}\right)\right]_{\mathrm{A}},\left[\operatorname{Exh}\left(Q, p_{\mathrm{c}}\right)\right]_{\mathrm{A}}\right\}$, but one of these three propositions could be a logical contradiction (If $\mathrm{A}$, for example, entails the negation of $p_{\mathrm{a}}$ ). The alternative to Dayal's presupposition that I will suggest in (20) will guarantee equality. 
informative true member since the set is closed under conjunction $\left(p_{x \oplus y} \Leftrightarrow p_{x} \wedge p_{y}\right)$. Once again, this presupposition guarantees that the cells in the Contextual Partition are each identifiable by applying Exh to a member of the question denotation.

(15) Who/which girls (among a, b and c) came to the party?

$$
\begin{aligned}
& \mathrm{Q}=\left\{\mathrm{p}_{\mathrm{a}}, \quad \mathrm{p}_{\mathrm{b}}, \quad \mathrm{p}_{\mathrm{c}},\right. \\
& \mathrm{p}_{\mathrm{a} \oplus \mathrm{b}}, \quad \mathrm{p}_{\mathrm{a} \oplus \mathrm{c}}, \quad \mathrm{p}_{\mathrm{b} \oplus \mathrm{c}}, \\
& \left.\mathrm{p}_{\mathrm{a} \oplus \mathrm{b} \odot \mathrm{c}}\right\}
\end{aligned}
$$

(*seven propositions corresponding to the plural individuals in the restrictor*)

Presupposition: one of the seven propositions is true.

(Eliminates one cell in the Logical Partition.)

$$
\begin{aligned}
& \operatorname{Partition~}_{\mathrm{C}}(\mathrm{Q}, \mathrm{A}) \subseteq\left\{\left[\mathrm{p}_{\mathrm{a}} \& \neg \mathrm{p}_{\mathrm{b}} \& \neg \mathrm{p}_{\mathrm{c}}\right]_{\mathrm{A}}, \quad\left[\mathrm{p}_{\mathrm{b}} \& \neg \mathrm{p}_{\mathrm{a}} \& \neg \mathrm{p}_{\mathrm{c}}\right]_{\mathrm{A}}, \quad\left[\mathrm{p}_{\mathrm{c}} \& \neg \mathrm{p}_{\mathrm{a}} \& \neg \mathrm{p}_{\mathrm{b}}\right]_{\mathrm{A}},\right. \\
& {\left[p_{\mathrm{a} \oplus \mathrm{b}} \& \neg p_{\mathrm{c}}\right]_{\mathrm{A}}, \quad\left[\mathrm{p}_{\mathrm{a} \propto \mathrm{c}} \& \neg \mathrm{p}_{\mathrm{b}}\right]_{\mathrm{A}}, \quad\left[\mathrm{p}_{\mathrm{b} \odot \mathrm{c}} \& \neg \mathrm{p}_{\mathrm{a}}\right]_{\mathrm{A}},} \\
& \left.\left[\mathrm{p}_{\mathrm{a} \odot b_{\odot \circ}}\right]_{\mathrm{A}}\right\} \\
& {\left[=\left\{\left[\operatorname{Exh}\left(Q, p_{\mathrm{a}}\right)\right]_{\mathrm{A}}, \quad\left[\operatorname{Exh}\left(Q, p_{\mathrm{b}}\right)\right]_{\mathrm{A}},\left[\operatorname{Exh}\left(Q, p_{\mathrm{c}}\right)\right]_{\mathrm{A}},\right.\right.} \\
& {\left[\operatorname{Exh}\left(Q, p_{a \odot b}\right)\right]_{\mathrm{A}}, \quad\left[\operatorname{Exh}\left(Q, p_{a \odot c}\right)\right]_{\mathrm{A}},\left[\operatorname{Exh}\left(Q, p_{b \odot c}\right)\right]_{\mathrm{A}},} \\
& \left.\left.\left[\operatorname{Exh}\left(Q, p_{a \ominus b \odot c}\right)\right]_{\mathrm{A}}\right\}\right]
\end{aligned}
$$

\subsubsection{Inferences of admissible questions}

Recent accounts of negative islands have agreed that Dayal's presupposition is a necessary component in the explanation (Abrusán, 2007, 2014; Abrusán and Spector, 2011; Fox and Hackl, 2006; Schwarz and Shimoyama, 2011). Specifically, they all share the assumption that a negative island results from Maximality Failure (MF) - a question denotation that cannot possibly have a maximally informative true member, as demanded by Dayal's presupposition. Consider the contrast in (16). (16)a is an ordinary degree question sensitive to negative Islands, as shown in (16)b. The fact that the island is ameliorated by the introduction of the modal allowed in (16)c has been taken to argue that MF is the source of unacceptability. (See Fox, 2007b for a discussion of why amelioration would follow under any MF account of the negative island.)

(16) a. Tell me how fast you drove.

b. *Tell me how fast you didn't drive.

c. Tell me how fast you are not allowed to drive.

I will illustrate why this might be the case focusing on Fox and Hackl's (2006) account. Under this account, degree domains are densely ordered, and consequently the denotations of all of the questions in (16) consist of infinite sets of propositions, densely ordered by entailment. In (16)b, but not in (16)a or (16)c, this leads to MF. The question in (16)a denotes the set of propositions in (17)a. This set, although densely ordered by entailment, will have a maximally informative true member, the proposition $\lambda w$. Speed $(y o u, w) \geq d^{*}$ where $d^{*}$ is the addressee's actual speed of driving.

\section{(17) Denotations of Questions in (16)}

a. $\quad$ In (16)a, $Q=\left\{\lambda w\right.$. Speed $($ you,w $\left.) \geq d: d \in D_{d}\right\}$

b. $\quad$ In (16)b, $Q=\left\{\lambda\right.$ w. Speed (you,w) $<\mathrm{d}$ : $\left.d \in D_{d}\right\}$

c. $\quad$ In $(16) \mathrm{c}, \mathrm{Q}=\left\{\lambda \mathrm{w} . \forall \mathrm{w}^{\prime} \in \mathrm{MB}_{\mathrm{w}} \operatorname{Speed}\left(\right.\right.$ you, $\left.\left.\mathrm{w}^{\prime}\right)<\mathrm{d}: \mathrm{d} \in \mathrm{D}_{\mathrm{d}}\right\}$ 
The question in (16)b, however, will never have a maximally informative true member. For any degree $\mathrm{d}$ higher than $\mathrm{d}^{*}$, the proposition $\lambda w$. Speed $(y o u, w)<d$ will be true, and the propositions will be more informative the smaller $d$ is. Since there is no smallest degree greater than $\mathrm{d}^{*}$ in the densely ordered domain of degrees, Dayal's presupposition cannot be satisfied. The effect of the modal follows as well. For example, if the modal base entails the proposition $\lambda$ w.Speed(you,w) $<d^{\prime}$ but doesn't entail anything beyond that, then $\lambda w . \forall w^{\prime} \in M B_{w} \operatorname{Speed}\left(y o u, w^{\prime}\right)<d^{\prime}$ will, of course, be the most informative true proposition in the set. The logic is outlined in (18).

\section{(18) Let $T(Q, @)$ be the set of true members of $Q$ in world @ and $d{ }^{*}$ be the addressee's speed in $\mathbf{w}$ :}
a.
In (16)a $T(Q, @)=\left\{\lambda w\right.$. Speed $($ you,w $\left.) \geq \mathrm{d}: \mathrm{d} \leq \mathrm{d}^{*} @\right\}$
This set has a strongest member since $\left\{\mathrm{d}: \mathrm{d} \leq \mathrm{d}^{*} *_{@}\right\}$ has a maximum
b. In $(16) b, T(Q, @)=\left\{\lambda w . S p e e d(\right.$ you,w $\left.)<d: d>d^{*} @\right\}$
This set has no strongest member because $\left\{\mathrm{d}: \mathrm{d}>\mathrm{d}^{*}{ }_{\varrho}\right\}$ has no minimum.
c. In (16)c, $T(Q, @)=\left\{\lambda \mathrm{w} . \forall \mathrm{w}^{\prime} \in \mathrm{MB}_{\mathrm{w}} \operatorname{Speed}\left(\right.\right.$ you, $\left.\left.\mathrm{w}^{\prime}\right)<\mathrm{d}: \forall \mathrm{w}^{\prime} \in \mathrm{MB}_{\varrho}\left[\mathrm{d}>\mathrm{d}^{*}{ }_{\mathrm{w}^{\prime}}\right]\right\}$
This set could have a strongest member because $\left\{\mathrm{d}: \forall \mathrm{w}^{\prime} \in \mathrm{MB}_{\varrho}\left[\mathrm{d}>\mathrm{d}^{*}{ }_{\mathrm{w}}\right]\right\}$ could have a minimum.

And, once more, whenever it is presupposed that $\mathrm{Q}$ has a strongest true member, every cell in Partition $_{\mathrm{C}}(\mathrm{Q}, \mathrm{A})$ (where A is the context-set) will be identifiable using Exh.

\subsection{Interim summary}

In this introductory section we have seen two empirical arguments for Dayal's presupposition, one coming from negative islands and the other from the inferences speakers draw from ordinary $w h$-questions. We also provided a possible conceptual motivation for the presupposition, namely that it eliminates an arithmetic problem we identified, stemming from our putative constraint requiring that a question be answerable by a single member of the question denotation. Specifically, we have seen in (12) that if Dayal's presupposition is met, cell identification in (19) is met as well.

(19) Cell Identification (CI): A question Q and a context-set A meet Cell Identification if

$$
\forall \mathrm{C} \in \operatorname{Partition}_{\mathrm{C}}(\mathrm{Q}, \mathrm{A}) \exists \mathrm{p} \in \mathrm{Q}\left([\operatorname{Exh}(Q, p)]_{\mathrm{A}}=\mathrm{C}\right) .
$$

It is easy to see that the converse holds as well: if CI is met, so is Dayal's presupposition (if Exh receives the definition in (11)). In light of this equivalence, we might ask which is the basic requirement imposed by grammar. What I will suggest in this paper is that it is CI. This suggestion will be based on two different empirical considerations. The first, from negative islands, will motivate a strengthening of the requirement from questions, which will be very natural if $\mathrm{CI}$ is the basic condition (but will make less sense otherwise). ${ }^{12}$ Specifically, we will see reasons to think that it is not only true that every cell in the Contextual Partition must

\footnotetext{
${ }^{12}$ See Fox, 2010 where I propose a different constraint on questions. Evaluating the argument for CI based on negative islands will thus require some conceptual assessment.
} 
be identifiable by a member of Q, but that the converse must also hold - every member of Q must identify a cell (Non-Vacuity, NV). These two requirements together yield the demand of Question Partition Matching:

(20) Question Partition Matching (QPM): A question Q and a context-set A meet QPM if they meet $\mathrm{CI}$ and Non-Vacuity (NV)

a. $\quad \mathrm{CI}: \forall \mathrm{C} \in \operatorname{Partition}_{\mathrm{C}}(\mathrm{Q}, \mathrm{A}) \exists \mathrm{p} \in \mathrm{Q}\left([\operatorname{Exh}(Q, p)]_{\mathrm{A}}=\mathrm{C}\right)$ and

b. $\quad \mathrm{NV}: \forall \mathrm{p} \in \mathrm{Q} \exists \mathrm{C} \in \operatorname{Partition}_{\mathrm{C}}(\mathrm{Q}, \mathrm{A})\left([\operatorname{Exh}(Q, p)]_{\mathrm{A}}=\mathrm{C}\right)$

The second empirical argument will be based on MS, which is a counter-example to $A n s_{D}$. We will see that it is not a counter-example to CI (or to the stronger QPM) if we move to a different theory of Exh, one which has been supported in the domain of Scalar Implicatures. ${ }^{13}$

The remainder of the paper is organized as follows. In section 2, I will further explain the two challenges just mentioned for Dayal's semantics, which in sections 3 and 4 will serve to argue for QPM. In sections 5 through 7 I will discuss various predictions that are made regarding the distribution of MS.

\section{Challenges for Dayal's semantics}

\subsection{Mention Some}

According to Dayal the answer to a question, Q, is the most informative true member of Q (hence the presupposition). This answer entails all true members of $\mathrm{Q}$ and is thus never an MS answer. ${ }^{14}$ So, for example, $A n s_{D}$ can deliver only one type of argument to the responsive predicates know and forget in (21) and this argument would derive the MA reading. The MS reading is simply not derivable. (If Mary knows just one among the many locations where we can get gas, she does not know a true member of the Hamblin denotation that entails all other true members.)

(21) Mary knows where we can get gas in Cambridge.

mention some (MS)

Mary knows one location where we can get gas. mention all (MA)

Mary knows all locations where we can get gas.

It is, thus, reasonable to conclude that $A n s_{D}$ sometimes demands too much from a question.

\footnotetext{
${ }^{13}$ As we will see in section 4, the second argument can also be accommodated without directly imposing CI. What is crucial, however, is that we revise $A n s_{D}$, so that it makes explicit reference to Exh (and in particular, to a definition of Exh that can account for FC inferences).

${ }^{14}$ It is equivalent to Weak Exhaustivity whenever Dayal's presupposition is met.
} 


\subsection{Higher order quantification - a mysterious Negative Island (Spector, 2008)}

Spector (2008) identified a new type of wh-question, which he analyzed as involving higher order quantification. He then showed that this type of question is sensitive to negative islands, a fact that does not follow from Dayal's presupposition. Since the sensitivity to negative islands is so similar to what we see in cases that do follow from Dayal's presupposition, this suggests that $A n s_{D}$ sometimes demands too little from a question.

\subsubsection{Higher order quantification}

Consider the sentences in (22). Under standard assumptions, whPs quantify over ordinary individuals - type e. The predicted Hamblin denotation for both questions in (22) is, therefore, the set of propositions $\left\{\mathrm{p}: \exists \mathrm{x}_{\mathrm{e}} \in \mathrm{R}\left[\mathrm{p}=\lambda \mathrm{w}\right.\right.$.Required $\mathrm{w}_{\mathrm{w}}\left(\lambda \mathrm{w}^{\prime}\right.$. We $\operatorname{read}_{\mathrm{w}^{\prime}} \mathrm{x}$ for this class)] \}, where $\mathrm{R}$ is a subset of $\mathrm{D}_{\mathrm{e}}$ (the denotation of the $w h$ Ps restrictor).

(22) a. What are we required to read for this class?

b. Which books are we required to read for this class?

A complete answer would then specify all the things in $\mathrm{R}$ we are required to read (as well as all of the things in $\mathrm{R}$ that we are not required to read). Imagine that no such things exist. By the standard assumptions, the answer would either be undefined (if $A n s_{D}$ is indeed an obligatory operator) or (if not) it might simply state that there is nothing that we are required to read.

With this in mind, Spector asks us to imagine a situation where, despite there being no particular thing we are required to read (no book, paper, reading material, etc.), there are still requirements pertaining to reading, for example, a situation where it is required that we either read all of the Russian books on the reading list or all of the French books and that the choice among these two options is left for us to make.

Now consider what would happen if we embed one of the questions in (22) under a responsive (veridical) predicate yielding a sentence of the form $x V$ what we are required to read, as in (23). If standard assumptions hold, the resulting statement would either be a presupposition failure or the statement that Mary stands (at the relevant time) in the $V$ relation to the proposition that there is nothing we are required to read. It is not clear whether the sentences have this interpretation (a fact that might be attributed to Dayal's presupposition). But the sentences definitely do have a different salient interpretation, one that is true just in case Mary stands in the $V$ relation to a proposition that expresses a disjunctive requirement. ${ }^{15}$ This does not follow from standard assumptions.

(23) a. Mary knows/forgot what we are required to read.

b. Mary knows/forgot which books we are required to read.

\footnotetext{
${ }^{15}$ As we will see in section 6, such an interpretation (higher-type) is not available with an English singular whP (e.g. which book).
} 
So what needs to change in order to derive this salient interpretation? Spector claims that the $w h \mathrm{P}$ needs to quantify over objects of a higher type than simple individuals, specifically he suggests upward entailing generalized quantifiers. This suggestion can be implemented with the assumption that the restrictor of a $w h \mathrm{P}$, a set of individuals, $\mathrm{R}$, can be shifted to a set of upward entailing generalized quantifiers over $\mathrm{R}$ (leaving a trace of the appropriate type). ${ }^{16}$

\section{(22)' Higher-Order Quantification:}

LF: Wh shift(restrictor) $\lambda \mathrm{Q}_{\mathrm{ett}} \mathrm{we}_{1}$ are required $\mathrm{Q} \lambda \mathrm{x}$. $\mathrm{PRO}_{1}$ to read $\mathrm{x}$ for this class?

Denotation: $\left\{p: \exists Q \in U G Q(R)\left[p=\lambda w . \operatorname{Required}_{w}\left(\lambda w^{\prime}\right.\right.\right.$.

$$
\left.\left.\mathrm{Q}\left(\left\{\mathrm{x}: \text { We } \operatorname{read}_{\mathrm{w}^{\prime}} \mathrm{x} \text { for this class }\right\}\right)\right]\right\},
$$

Where $\mathrm{UGQ}(\mathrm{R})$ is the set of upward entailing generalized quantifiers that live on $\mathrm{R}$.

With this in place, we can account for the attested interpretation. The answer to the question would have to specify which propositions in the denotation are true, and since the disjunction of (the Montague Lift of) two plural individuals in $\mathrm{R}$ is a generalized quantifier over $\mathrm{R}$, the proposition that the disjunction is required will be in the question denotation. And, of course, Dayal's presupposition would be satisfied. ${ }^{17}$

\subsubsection{Sensitivity to Negative Islands}

Spector presents evidence from ellipsis that higher order quantification is real and sensitive to negative islands. Consider the question answer pairs in (24) and (25). The answers (all quantificational fragments) show an ambiguity that can be explained if higher order quantification is available along with standard quantification over individuals. If the $w h$ trace ranges over simple individuals, the quantifier in the fragment answer will have scope over the modal required. If the trace ranges over generalized quantifier, the modal will have wide scope. $^{18}$

(24) What are you required to read for this class?

War and Peace or Brothers Karamazov.

$$
\text { (Required }>\text { or; or }>\text { required) }
$$

(25) Which books are you required to read for this class?
a. The Russian books or the French books.
(Required $>$ or; or $>$ required)
b. Three Russian books.
c. $[\mathrm{MB}$ or $\mathrm{SE}]$ and $[\mathrm{W} \& \mathrm{P}$ or $\mathrm{BK}]$
(required $>3 ; 3>$ required)
(required $>$ or; or $>$ required)

\footnotetext{
${ }^{16}$ The restriction to upward entailing quantifiers is needed to account for the fact that the answer to (22) need not specify prohibitions. For a possible way of deriving this restriction, see note 48 .

${ }^{17}$ To derive a non-trivial existence presupposition for (13) and (22), we would need to restrict or modify highertype readings. The proposal made in section 3 would rule out a higher type readings for (13) but not for (22). To derive the presupposition that some requirement was made (in place for me at least in (22)b), one would need to remove the tautological GQ from the domain of quantification. This will be achieved if the type-shift rule is stated as in note 48 .

${ }^{18}$ Of course a full account of the connection between the representation of the question and of the fragment requires specific assumptions about the analysis of fragment answers. For concreteness, we can adopt the assumption that fragments involve ellipsis which must satisfy a Parallelism condition of the sort argued for in Rooth, 1992). This would probably require the assumption that whPs have a landing site above the subject and below the interrogative C (see Romero, 1998).
} 
The unavailability of narrow scope for the quantifier in the fragment answer in (26) can be seen to demonstrate that the construction is sensitive to negative islands. This is further supported by the observation of modal obviation in (27), corresponding to what we've seen in (16)c.

(26) What did you not read for this class?

War and Peace or Brothers Karamazov.

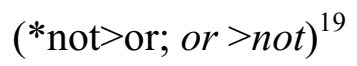

What are you not allowed to read for this class?

War and Peace or Brothers Karamazov.

$(?$ not $>$ or $;$ or $>$ not $)$

In the case of degree expressions, modal obviation provided support for the claim that Dayal's presupposition is involved in the account. So one would hope that Dayal's presupposition will provide an account here as well. But this is not the case. If you read everything but War and Peace and brothers Karamzov, the proposition that you didn't read War and Peace or Brothers Karamzov (not $>$ or) would be the most informative true member of the question denotation. Thus, Dayal's presupposition would be satisfied with higher order quantification and we would expect the fragment answer in (26) to be acceptable on the not $>$ or representation. ${ }^{20}$

So here is where we are now. In 2.1. the MS interpretation of questions was taken to reveal an area where $A n s_{D}$ demands too much from a question. Here we see a place where it arguably demands too little. In the next two sections, I will propose a resolution for these two problems (of under- and over-generation), beginning with the latter. The resolution in both cases will be based on the idea that the relevant question presupposition stems from the problem of question duality discussed in section 1 - from the need to connect the question denotation to the partition it induces. The problem of over-generation will be resolved by strengthening CI and demanding that the mapping between questions and partitions meet NV as well, as in (20). The problem of under-generation will be resolved once we move to a more sophisticated theory of the mapping (between denotation and partition), namely a theory of exhaustivity that can account for free choice inferences.

\footnotetext{
${ }^{19}$ A way to see that not $>$ or is ruled out is to track "ignorance inferences" - to observe the obligatory inference that the speaker does not know whether W\&P was read (and likewise for BK). If not $>$ or were possible, the fragment (when exhaustified) could provide a complete answer to the question, which would be associated with no ignorance inferences.

${ }^{20}$ One might suggest to rule out higher order quantification for (26) based on the observation that the resulting interpretation is not sufficiently distinct from the basic interpretation. Specifically, higher order quantification yields the same partition as the one induced by the more basic semantic type. This could account for the restriction along with an appropriately stated economy condition (along the lines of e.g., Reinhart, 1983 or Fox, 2000). But stating the economy condition so that it would still allow for higher order quantification in (21) is not trivial (see (33)). For an argument that higher order quantification is indeed available in (21) (independently of my account of MS) consider the availability of Free Choice in the fragment answer, which, on many accounts, requires $c a n>$ or.
}

(i) Where can we get gas?

Either at the Shell station or the pump across the street. (Free choice available $\rightarrow$ can $>o r$ ) 


\section{Over-generation and Question PartitionMatching}

As mentioned in section 1, Dayal's presupposition is equivalent to the demand that every cell in the Contextual Partition be identifiable (via Exh, as defined in (11)) by a member of Q (CI). We will now see that the problem of over-generation exemplified by the unacceptability of not>or in (26) is resolved the moment we add to CI the converse requirement of NonVacuity, yielding the requirement of QPM defined in (20) repeated below:

(20) Question Partition Matching (QPM): A question Q and a context-set A meet QPM if they meet $\mathrm{CI}$ and Non-Vacuity (NV)

$$
\begin{array}{ll}
\text { a. } & \mathrm{CI}: \forall C \in \operatorname{Partition}_{\mathrm{C}}(\mathrm{Q}, \mathrm{A}) \exists \mathrm{p} \in \mathrm{Q}\left([\operatorname{Exh}(Q, p)]_{\mathrm{A}}=\mathrm{C}\right) \text { and } \\
\text { b. } & \mathrm{NV}: \forall \mathrm{p} \in \mathrm{Q} \exists \mathrm{CC} \in \operatorname{Partition}_{\mathrm{C}}(\mathrm{Q}, \mathrm{A})\left([\operatorname{Exh}(Q, p)]_{\mathrm{A}}=\mathrm{C}\right)
\end{array}
$$

For not to outscope or in the fragment answer in (26) the antecedent question would require higher order quantification (as in (22)' for (22)). In other words, the antecedent question in (26) would have to receive the LF representation and semantic denotation in (26)':

(26)' Higher-order quantification:

LF: Wh shift(restrictor) $\lambda Q_{\text {ett }}$ Not $\mathrm{Q} \lambda \mathrm{x}$. we read $\mathrm{x}$ for this class?

Denotation: $\left\{\mathrm{p}: \exists \mathrm{Q} \in \mathrm{UGQ}(\mathrm{R})\left[\mathrm{p}=\lambda \mathrm{w} .\left\{\mathrm{x}: \mathrm{We} \operatorname{read}_{\mathrm{w}} \mathrm{x}\right.\right.\right.$ for this class $\left.\} \notin \mathrm{Q}\right\}$, Where $U G Q(R)$ is the set of upward entailing generalized quantifiers that live on $R$.

The question denotation is guaranteed to have a maximally informative true member, thus satisfying CI (equivalent, at the moment, to Dayal's presupposition). ${ }^{21}$ However, it will not satisfy NV, at least if there are two or more objects in R. To see this, assume that $b_{1} \in R$ and $b_{2} \in R$. The conjunction of the (Montague-Lift) of the two will be a member of UGQ(R), and the proposition in (28) will be in the question denotation. Since this proposition is too weak to be the maximally informative true member of $\mathrm{Q}$, there is no way for $\mathrm{NV}$ to be satisfied. ${ }^{22}$

$$
\lambda \mathrm{w} . \neg\left(\left[\mathrm{We} \operatorname{read}_{\mathrm{w}} \mathrm{b}_{1} \text { for this class }\right] \wedge\left[\mathrm{We} \mathrm{read}_{\mathrm{w}} \mathrm{b}_{2} \text { for this class }\right]\right)
$$

A weak proposition of this sort $(\neg>\wedge)$ will always be in the question denotation. ${ }^{23}$ And since such a proposition can never be a maximally informative true member, NV will never

\footnotetext{
${ }^{21}$ This equivalence will break down in section 4.

${ }^{22}$ Applying Exh, as defined (11), to this proposition will yield a contradiction. Note that nothing changes if we move to a theory of Exh that does not yield contradictions in cases of this sort (e.g. G\&S 1994; Fox, 2007a, BarLev and Fox, 2017). In all of these theories, Exh yields a meaning that is necessarily weaker than a cell in the partition.

${ }^{23}$ An obvious question that could be raised at this stage is whether the question denotation can be contextually restricted (or pruned), by, e.g., a covert restrictor, C conjoined with the current restrictor of the $w h \mathrm{P}$ $(\mathrm{UGQ}(\mathrm{R}) \cap \mathrm{C})$. The worry is that such contextual restriction could prune (28) [and all other propositions that lead to a violation of NV] from the question denotation leading to an acceptable result. (See Fox and Hackl, 2006 and subsequent work on negative islands where a very similar issue arises.) To rule this pruning out, I would like to appeal to constraints on pruning introduced in the context of work on exhaustivity (Bar-Lev, 2018; Crnič et. al., 2015; Fox and Katzir, 2011; Katzir, 2014; Magri, 2009, 2011). For example, assume with Fox and Katzir, that a proposition $\mathrm{p}$ can be pruned from a set of propositions $\mathrm{Q}$ only if the resulting question [Q - $\{\mathrm{p}\}]$ makes p irrelevant. This constraint on pruning would rule-out pruning of (28) given that it is the disjunction of two non-pruned alternatives (and relevance, as it was defined in section 1, is closed under Boolean operators). See also notes 32 and 37.
} 
be satisfied in this environment. ${ }^{24,25}$ The moment additional quantificational expressions are introduced above the wh-trace, as in (27), things will change (for certain Context-sets) for the reasons discussed in Fox, 2007b - generalizing observations in Fox and Hackl, 2006. ${ }^{26}$ For example, the corresponding proposition to (28) in the case of (27) will be the following:

$$
\lambda \mathrm{W} . \neg \text { Allowed }_{\mathrm{w}}\left(\left[\mathrm{We} \text { read } \mathrm{b}_{1} \text { for this class }\right] \wedge\left[\text { We read } \mathrm{b}_{2} \text { for this class }\right]\right)
$$

And this proposition can be the most informative true proposition in the Hamblin set associated with higher order quantification. So Question Partition Matching accounts for the negative island and its obviation by appropriately selected modals.

\section{Under-generation and an alternative definition of $\boldsymbol{E x h}^{27}$}

The over-generation problem for Dayal's proposal was resolved in the previous section by strengthening the presupposition associated with interrogative constructions. I suggested that such constructions are not just subject to Dayal's maximality requirement. They are also subject to $\mathrm{NV}$ - the requirement that every proposition in the question denotation identify a cell in the Contextual Partition. Now I would like to argue that the problem of undergeneration (MS) indicates that interrogative constructions are, in fact, not subject to maximality in the first place and that this requirement should be replaced with cellidentification, CI.

$A n s_{D}$ takes a set of propositions, Q, and a world, w, as input and returns the maximally informative among the true propositions in the set. From this it follows, as we saw in 2.1., that the answer to a question provides all of the true "positive" information (i.e. is equivalent to "weak exhaustivity", whenever defined). ${ }^{28}$ And this is why $A n s_{D}$ yields MA in (21), repeated below, and cannot account for MS.

(21) Mary knows where we can get gas in Cambridge.

mention some (MS)

\footnotetext{
${ }^{24}$ I also predict no higher order quantification for simple questions such as what did you read?, as apposed to what are we required to read? I haven't figured out a way to test this prediction directly, though I should note that, on the one hand, it is supported by the existence presuppositions of the sentences in (Error! Bookmark not defined.) [but see note 17 and 25], and, on the other hand, it might be disconfirmed by the proposal in Elliott, Nicolae and Sauerland 2018.

25 As it stands, the proposal can't be right. The contradictory GQ is an UE GQ living on R, and the resulting proposition cannot be in the question denotation if QAP is a requirement. So we need to change the type shift rule. But the type shift rule needs to change on independent grounds, see section 6.1. The proposal made in footnote 48 would eliminate the problem.

${ }^{26}$ Let Op be a universal modal. The relevant logical fact is that for every set of propositions $\mathrm{Q}$, and contingent proposition $\mathrm{p} \in \mathrm{Q}$, it is possible for $\lambda \mathrm{w} . \mathrm{OP}(\mathrm{w}, \mathrm{p})$ to be the maximally informative true member in $\{\lambda \mathrm{w} . \mathrm{OP}(\mathrm{w}, \mathrm{q})$ : $\mathrm{q} \in \mathrm{Q}\}$.

${ }^{27}$ The proposal made in this section is one of two proposals I considered in Fox 2013 and Fox 2015. The other proposal I entertained is incompatible with Dayal's account of the presupposition of singular wh questions. See Xiang (2015) for relevant discussion.

${ }^{28}$ To repeat, an answer to a question is the proposition that identifies the correct cell in the partition, but it is not the actual cell. If it were the cell, we would not have the argument from Heim that questions do not denote partitions directly - though the picture is more subtle if the proposals in Spector and Egré (2015) are adopted. See notes 39 and 40 .
} 


\section{Mary knows one location where we can get gas. mention all (MA) \\ Mary knows all locations where we can get gas.}

The problem of under-generation suggests that Dayal's maximality requirement is too demanding. But, shouldn't it suggest the same for the requirement of CI? After all, haven't we shown in 1.4. that the two requirements are equivalent? The answer is subtle. Equivalence holds but only if the proposed method of cell-identification relies on maximality (if the function from propositions to cells is $\left.\left.\lambda p . \lambda w \cdot\left[\operatorname{Max}_{i n f}(Q, w)=p\right]\right]_{A}\right)$. The method of cell identification that comes out of current work on scalar implicatures breaks the equivalence and, I would like to suggest, resolves the problem.

More specifically, I would like to suggest that the MS challenge stems from an incomplete theory of exhaustification. ${ }^{29}$ Once we move to a more accurate theory (based on considerations that come from the domain of scalar implicatures), we will see that the requirement of CI makes the right predictions. Specifically, we will see that there are cases where $p$ can identify a cell by exhaustification, though $p$ is not the most informative true member of Q. These cases, if I am right, are precisely the cases where MS arises.

Assume that there are $n$ relevant locations and let $\measuredangle l_{\mathrm{i}}$ stand for the proposition that we can get gas in the $\mathrm{i}$-th location (and $\mathrm{l}_{\mathrm{i}}$ stand for the proposition that we do so). Assume that the correct cell in the partition induced by a question is the proposition that we can get gas in the first and second location and nowhere else $\left(\left\langle\mathrm{l}_{1} \wedge \backslash \mathrm{l}_{2} \wedge \neg \backslash \mathrm{l}_{3} \wedge \neg\left\langle\mathrm{l}_{4} \ldots \wedge \neg\left\langle\mathrm{l}_{\mathrm{n}}\right){ }^{30}\right.\right.\right.$ If CI must hold, this cell needs to be identified by a proposition in the question denotation via exhaustification. But if Exh is defined as in (11) above $\left[\operatorname{Exh}(Q, p, w) \Leftrightarrow\left[\operatorname{Max}_{i n f}(Q, w)=p\right]\right]$, only MA can be derived. So this, I would like to claim, is the source of the problem.

With a more sophisticated theory of exhaustification (one that accounts for the conjunctive interpretation of disjunction in certain modal contexts), we will see that the MS/MA ambiguity can be attributed to an ambiguity in the question denotation. In the case of MA, the question denotation will be such that one of its members will identify a cell only if it contains all the positive true information. (In our case $\left\langle 1_{1} \wedge \backslash l_{2}\right.$ will be the cell identifier.) In the case of MS, a cell-identifier can be a relatively weak proposition; in our case it will be the proposition $\diamond\left(1_{1} \vee l_{2}\right)$ [ $\left.=\left(\diamond 1_{1} \vee \diamond l_{2}\right)\right]$. I will show that this can explain MS under a natural modification in the answer operator (in addition to the modification that automatically results from the alternative theory of $E x h$ ). Moreover we will see that the necessary ambiguity in the question denotation is already in place, given the observations made in section 3.

Though our overall goal is to replace Dayal's presupposition with QPM (CI+NV), we can, nevertheless flesh out the argument made in this section using Dayal's operator in (9), restated with Exh replacing Max $_{\text {inf }}$ (as suggested in (11)).

\footnotetext{
${ }^{29}$ This I share with Schulz and van Rooij (2006), though the theory of exhaustivity that I have is very different from theirs, as are the resulting predictions.

${ }^{30}$ As we will see, the cells are identical for MS and MA only if we keep to context-sets in which you never (even in any of the allowed worlds) get gas in more than one location (something which will require pruning of propositions from the question denotation, if NV is to hold - see notes 23,32 and 37).
} 
(30) $\operatorname{Ans}_{\mathrm{D}}(\mathrm{Q})=\lambda \mathrm{w}: \exists \mathrm{p} \in \mathrm{Q}[\operatorname{Exh}(\mathrm{Q}, \mathrm{p}, \mathrm{w})=1] . \mathrm{\iota p} \in \mathrm{Q}[\operatorname{Exh}(\mathrm{Q}, \mathrm{p}, \mathrm{w})=1]$

where $\operatorname{Exh}(Q, p, w) \Leftrightarrow\left[\operatorname{Max}_{\text {inf }}(Q, w)=p\right]$

Using this format, MS will suggest two modifications in Dayal's proposal. The first is what I said above: the adjustment of the presuppositional requirement that follows the moment the Max $_{\text {inf }}$ definition of Exh is replaced with one that derives the free choice interpretation of disjunction in modal contexts (FC), thereby explaining how $\downarrow\left(1_{1} \vee l_{2}\right)$ can identify a cell. The second modification pertains just to the output of the function, which will now not be a proposition but a set of propositions (later to serve as the restrictor of an existential quantifier) - see George, 2011. This set will consist not just of the cell-identifier but of all true propositions in Q that entail the cell-identifier. With this, the MS/MA distinction will be determined by the cardinality of the set. (MS will arise if and only if the set is not a singleton - whenever Q has true members that asymmetrically entail the cell-identifier.)

We will start in 4.1. with some background on FC, introducing, in particular, the view of exhaustification argued for in Bar-Lev and Fox, 2017, 2018. We will then discuss (in 4.2.) the consequences of Spector's assumptions (about higher order quantification, introduced in section 3) for the analysis of questions involving existential modals, such as that in (21). Finally (in 4.3.-4.5.), we will see how things can be put together to provide an account of the MS/MA ambiguity.

\subsection{Background on Free Choice}

Consider the sentence in (31) exemplifying FC. (31) involves a disjunctive sentence under the scope of an existential modal. ${ }^{31}$ As argued by Alonso Ovalle (2006) [building on Kratzer and Shimoyama 2002] the basic meaning of the construction is equivalent to matrix disjunction [just as in standard modal logic: $\diamond(C v I C)$ is equivalent to $\triangleleft C v \checkmark I C]$. If this is the case, the basic meaning needs to be strengthened to entail matrix conjunction, $\triangle C \& \triangle I C$. I will assume that the method of strengthening involves the covert operator Exh that yields standard scalar implicatures, as proposed in Fox, 2007a and further defended in Crnič, 2016; Bar-Lev, 2018; and Bar-Lev and Fox, 2017, henceforth B\&F.

$$
\begin{aligned}
& \text { Free Choice: } \\
& \text { You are allowed to have cake or ice cream. } \\
& \operatorname{Exh}(\mathrm{Q})(\diamond(\mathrm{C} \vee \mathrm{IC}))=\diamond \mathrm{C} \& \diamond \mathrm{IC} \&[\neg \backslash(\mathrm{C} \& \mathrm{IC})] \\
& {[\text { where } \mathrm{Q}=\{\searrow(\mathrm{C} v \mathrm{IC}), \diamond \mathrm{C}, \diamond \mathrm{IC}, \diamond(\mathrm{C} \& \mathrm{IC})\}]^{32}}
\end{aligned}
$$

\footnotetext{
${ }^{31}$ For evidence that this is indeed the syntactic scope and various approaches to counter-evidence, see Bar-Lev, 2018.

${ }^{32}$ To account for the optionality of the inference $\neg \checkmark(C \& I C)$ it is natural to appeal to the pruning of alternatives - the inference disappears if the alternative $\downarrow(C \& I C)$ is considered to be irrelevant hence pruned from $\mathrm{Q}$ (but see Fox, 2007a for a different account). Such pruning is consistent with the constraint argued for by Fox and Katzir, 2011 - a constraint crucial for understanding the impossibility of a conjunctive inference when the set of formal alternatives is closed under conjunction. See also note 23, as well as Chierchia, 2013; Katzir, 2014; Crnič et. al., 2015; and Singh et. al., 2016.
} 
In Fox (2007), a single occurrence of Exh could not yield the conjunctive result. Instead Exh needed to apply recursively till it reached a fixed point. Here I would like to adopt the alternative view of exhaustification proposed by B\&F, which takes cell-identification to be its defining property and is thus conceptually more in line with the proposal made here. (See Fox, 2013, 2015 where a third definition of Exh is pursued to account for MS.) Specifically, Exh takes a question, Q, and a proposition, p, and identifies a cell in the partition induced by $\mathrm{Q}$ (i.e. assigns a truth value to every member of Q) ${ }^{33}$ This is done as follows. First the truthvalue 0 is assigned to all of the innocently-excludable propositions (as in Fox 2007a) and then the remaining propositions are assigned the truth-value 1:

(32) Exhaustivity as Cell Identification (Simplification of Bar-Lev and Fox (2017)) $\operatorname{Exh}(\mathrm{Q}, \mathrm{p}, \mathrm{w})=1$ iff $\forall \mathrm{q} \in \mathrm{Q}[\mathrm{q} \in \mathrm{IE}(\mathrm{Q}, \mathrm{p}) \rightarrow \mathrm{q}(\mathrm{w})=0] \& \forall \mathrm{q} \in \mathrm{Q}[\mathrm{q} \notin \operatorname{IE}(\mathrm{Q}, \mathrm{p}) \rightarrow \mathrm{q}(\mathrm{w})=1]$

Where $\operatorname{IE}(\mathrm{Q}, \mathrm{p})$ is defined as in Fox, 2007a to be the intersection of all maximal consistent exclusions (that is

$\operatorname{IE}(Q, p)=\bigcap\{A: A$ is a maximal subset of $Q$, such that $\{p\} \cup\{\neg q: q \in A\}$ is a consistent set of propositions $\}$

It is easy to see that this yields the result in (31). The only member of $I E(Q, \nabla(C v I C))$ is the conjunctive alternative $\Delta(C \& I C)$. This alternative is assigned the truth-value 0 and all other members of $\mathrm{Q}$ are assigned the truth-value 1.

\subsection{Spector's ambiguity}

Consider the interrogative complement of the responsive predicate know in (21). By Spector's assumptions introduced in section 3, this construction can be associated with the two LFs in (21)': ${ }^{34}$

(21)' LFs for the complement of know in (21)

a. Low-Type Trace (distributivity applying above can)

Wh restrictor $\lambda x . C_{\text {int }}[\mathrm{x}$ dist $\lambda y$. can we get gas in $\mathrm{y}]$

Denotation: $\left\{\mathrm{p}: \exists X \in \mathrm{L}\left[\mathrm{p}=\lambda \mathrm{w} . \forall \mathrm{y} \in \operatorname{ATOM}(\mathrm{X}) \operatorname{Can}_{\mathrm{w}}(\lambda \mathrm{w}\right.\right.$ '. qe get $_{w^{\prime}}$ gas in $\left.\left.\left.y\right)\right]\right\}$

b. High-Type Trace

Wh shift(restrictor) $\lambda Q_{<e t . t>}$ can $Q \lambda x$. we get gas in $\mathrm{x}$

Denotation: $\left\{\mathrm{p}: \exists \mathrm{Q} \in \mathrm{UGQ}(\mathrm{L})\left[\mathrm{p}=\lambda \mathrm{w} \cdot \mathrm{Can}_{\mathrm{w}}\left(\lambda \mathrm{w}^{\prime}\right.\right.\right.$. $\mathrm{Q}\left(\left\{\mathrm{x}\right.\right.$ : we get $_{\mathrm{w}^{\prime}}$ gas in $\left.\left.\left.\left.\mathrm{x}\right\}\right)\right]\right\}$,

\footnotetext{
${ }^{33}$ The procedure is more sophisticated in $\mathrm{B} \& \mathrm{~F}$ (relying on innocent inclusion). As B\&F discuss, the definition in (32) is equivalent to B\&F's whenever applying (32) yields a non-contradictory proposition. The use of (32) is innocent in the context of this paper: If (32) yields a contradiction for a member of Q, (32) and B\&F's operator are not equivalent, but they both yield a result that violates NV (see note 22).

${ }^{34}$ Dist is a covert distribute operator that can combine with an individual and return a universal quantifier over the atomic parts of this individual (as in, e.g. Heim, Lasink and May, 1991). There are other possible representations that I am not discussing, e.g. a version of (21)'a in which dist is introduced below the modal. See Fox (2013) for discussion.
} 
The restrictor of the $w h$-phrase in (21)'a denotes a set of locations, L. Assume that there are three locations in $\mathrm{L}\left(\Lambda_{1}, \Lambda_{2}\right.$ and $\left.\Lambda_{3}\right)$ and keep to the shorthand introduced earlier $\left(1_{i}\right.$ stands for the proposition that we get gas at $\Lambda_{\mathrm{i}}$.). The denotation of (21)'a will then contain the following propositions (parallel to the basic case in (15)): ${ }^{35}$

\section{(21)"a Low-Type Trace denotation of (21) when there are three locations in $\mathbf{L}$}

The closure under conjunction of

$\left\{\lambda w \cdot \operatorname{Can}_{w}\left(\lambda w^{\prime}\right.\right.$. we get $_{w^{\prime}}$ gas in $\left.\Lambda_{1}\right), \lambda w \cdot \operatorname{Can}_{w}\left(\lambda w^{\prime}\right.$. we get $w^{\prime}$ gas in $\left.\Lambda_{2}\right)$,

$\lambda \mathrm{w} \mathrm{Can}_{\mathrm{w}}\left(\lambda \mathrm{w}^{\prime}\right.$. we get $_{\mathrm{w}^{\prime}}$ gas in $\left.\left.\Lambda_{3}\right)\right\}$

i.e.:

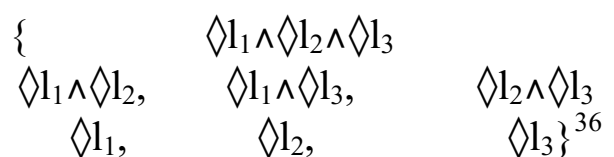

The denotation of (21)'b will contain propositions that you get by introducing quantifiers within the scope of the existential modal - UE quantifiers that live-on L. All such quantifiers can be written as disjunction of conjunctions (of the Montague-Lift) of the individuals in L. Imagine that we "prune" from this set all propositions involving non-trivial conjunctions (conjunctions of more than one conjunct). ${ }^{37}$ With such pruning we would get the following question denotation:

\section{(21)"b High-Type Trace denotation of (21) when there are three locations in $\mathbf{L}$

$\begin{array}{lll}\left\{\diamond 1_{1},\right. & \diamond 1_{2}, & \Delta 1_{3} \\ \diamond\left(l_{1} \vee l_{2}\right), & \diamond\left(1_{1} \vee l_{3}\right), & \nabla\left(l_{2} \vee l_{3}\right) \\ & \left.\Delta\left(l_{1} \vee l_{2} \vee l_{3}\right)\right\}\end{array}$

\subsection{The identified cells}

The two sets of propositions [(21)"a and (21)"b] induce the same Logical Partition. Both sets contain $\backslash 1_{1},\left\langle 1_{2}\right.$, and $\left\langle 1_{3}\right.$, as well as a few propositions that can be derived by Boolean combinations of these three propositions. In other words, every cell in the partition is characterized by specifying truth-values for $\left\langle 1_{1},{ }_{1}\right.$, and $\diamond 1_{3}$, which, in turn, determine the truth-values of the remaining members of either set:

\footnotetext{
${ }^{35}$ For example, $\measuredangle 1_{1} \wedge \backslash \mathrm{l}_{2}$ is the proposition $\lambda \mathrm{w} . \forall \mathrm{y} \in \mathrm{ATOM}\left(\mathrm{l}_{1} \oplus \mathrm{l}_{2}\right) \operatorname{Can}_{\mathrm{w}}\left(\lambda \mathrm{w}^{\prime}\right.$. We get $_{\mathrm{w}^{\prime}}$ gas in $\left.\left.\mathrm{y}\right)\right]$

${ }^{36}$ Closure under conjunction comes from Dayal's assumption that number neutral whP restrictors are closed under sum-formation together with the assumption that distributivity can apply above the existential modal. See Fox, 2013 for another possible account of MS (and its ultimate rejection), one which relies on low scope for the distributivity operator.

${ }^{37}$ This pruning satisfies the constraints introduced in note 23 (see also note 32 ). Pruning of $\searrow\left(l_{i} \wedge l_{k}\right)$ is crucial for satisfying NV whenever every world in the context-set falsifies $\downarrow\left(1_{i} \wedge l_{k}\right)$. Cases where pruning does not take place will not affect our results, but they will be harder to go over. I will have to leave the exercise to the interested reader.
} 
(33)

$$
\begin{aligned}
& \operatorname{Partition}_{\mathrm{L}}[(21) " \mathrm{a}]=\operatorname{Partition}_{\mathrm{L}}[(21) " \mathrm{~b}]=\left\{\neg \left\langle\mathrm { l } _ { 1 } \wedge \neg \left\langle\mathrm{l}_{2} \wedge \neg \backslash \mathrm{l}_{3}, \quad\left\langle\mathrm { l } _ { 1 } \wedge \neg \left\langle\mathrm{l}_{2} \wedge \neg \backslash \mathrm{l}_{3},\right.\right.\right.\right.\right.
\end{aligned}
$$

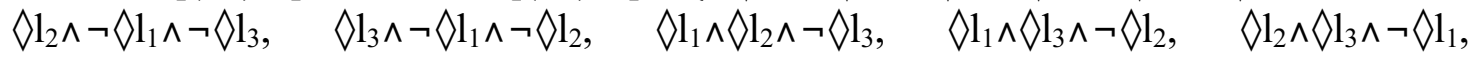

$$
\begin{aligned}
& \left\langle\mathrm{l}_{1} \wedge \backslash \mathrm{l}_{2} \wedge \backslash \mathrm{l}_{3}\right\}
\end{aligned}
$$

Morover, Exh, as defined in (32), will identify each of the cells for both (21)"a and (21)"b, except for the one in which $\measuredangle 1_{1}, \diamond 1_{2}$, and $\diamond l_{3}$ are all false (except for $\neg\left\langle 1_{1} \wedge \neg \backslash 1_{2} \wedge \neg\left\langle 1_{3}\right.\right.$ ), but see note 10:

$$
\begin{aligned}
& \text { a. } \quad \lambda \mathrm{w} \cdot \operatorname{Exh}\left([(21) " \mathrm{a}], \diamond \mathrm{l}_{1}, \mathrm{w}\right)=\lambda \mathrm{w} \cdot \operatorname{Exh}\left([(21) " \mathrm{~b}], \diamond \mathrm{l}_{1}, \mathrm{w}\right)=\left\langle\mathrm{1}_{1} \wedge \neg \backslash \mathrm{l}_{2} \wedge \neg \backslash \mathrm{l}_{3}\right. \\
& \text { b. } \quad \lambda w . \operatorname{Exh}\left(\left[(21)^{\prime \prime} \mathrm{a}\right], \diamond \mathrm{l}_{2}, \mathrm{w}\right)=\lambda \mathrm{w} \cdot \operatorname{Exh}\left(\left[(21)^{\prime \prime} \mathrm{b}\right], \diamond \mathrm{l}_{2}, \mathrm{w}\right)=\left\langle\mathrm{l}_{2} \wedge \neg \backslash \mathrm{l}_{1} \wedge \neg \Delta \mathrm{l}_{3}\right. \\
& \text { c. } \quad \lambda \mathrm{w} \cdot \operatorname{Exh}\left([(21) " \mathrm{a}], \diamond \mathrm{l}_{3}, \mathrm{w}\right)=\lambda \mathrm{w} \cdot \operatorname{Exh}\left([(21) " \mathrm{~b}], \diamond \mathrm{l}_{3}, \mathrm{w}\right)=\left\langle\mathrm{l}_{3} \wedge \neg \backslash \mathrm{l}_{1} \wedge \neg \Delta \mathrm{l}_{2}\right. \\
& \text { d. } \quad \lambda \mathrm{w} . \operatorname{Exh}\left([(21) " \mathrm{a}], \diamond \mathrm{l}_{1} \wedge \backslash \mathrm{l}_{2}, \mathrm{w}\right)=\lambda \mathrm{w} . \operatorname{Exh}\left([(21) " \mathrm{~b}], \diamond\left(\mathrm{l}_{1} \vee \mathrm{l}_{2}\right), \mathrm{w}\right)=\left\langle\mathrm{l}_{1} \wedge \diamond \mathrm{l}_{2} \wedge \neg \Delta \mathrm{l}_{3}\right.
\end{aligned}
$$

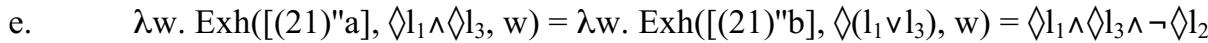

$$
\begin{aligned}
& \text { f. } \quad \lambda w . \operatorname{Exh}\left(\left[(21)^{\prime \prime} \mathrm{a}\right], \diamond \mathrm{l}_{2} \wedge \diamond \mathrm{l}_{3}, \mathrm{w}\right)=\lambda \mathrm{w} . \operatorname{Exh}\left(\left[(21)^{\prime \prime} \mathrm{b}\right], \diamond\left(\mathrm{l}_{2} \vee \mathrm{l}_{3}\right), \mathrm{w}\right)=\left\langle\mathrm{l}_{2} \wedge \diamond \mathrm{l}_{3} \wedge \neg \diamond \mathrm{l}_{1}\right. \\
& \text { g. } \quad \lambda w . \operatorname{Exh}\left([(21) " a], \diamond 1_{1} \wedge \Delta 1_{2} \wedge \diamond 1_{3}, w\right)=\lambda w . \operatorname{Exh}\left(\left[(21)^{\prime \prime} b\right], \diamond\left(1_{1} \vee l_{2} \vee l_{3}\right), w\right)=\diamond 1_{1} \wedge \diamond 1_{2} \wedge \diamond 1_{3}
\end{aligned}
$$

The first three cells are identified in the same way for the two questions: by application of Exh to one of the propositions $\Delta 1_{1}, \diamond 1_{2}$, and $\backslash 1_{3}$ - the weakest propositions in (21)"a and the strongest propositions in (21)"b. The other cells are identified by different propositions for the two questions, and, this, I claim is the source of the MS/MA distinction. If there is more than one location where one can get gas, the proposition that will identify the cell (when Exh applies to it) will mention all locations where one can get gas in the case of (21)"a [leading to an MA interpretation], and will not do so in the case of (21)"b [leading to MS].

\subsection{Answer returns a set of propositions}

Dayal's answer operator was stated in (30) as one that takes a set of propositions and returns the cell identifier if one exists (undefined otherwise). But the cell identifier under (30) is the maximally informative true member of the question denotation, and this, as already mentioned many times, will always derive MA (or presupposition failure). So our first modification, as mentioned, is to move to the B\&F definition of Exh in (32). Our second modification will be to have the Answer operator return not just the cell identifier but the set of true propositions that entail this cell identifier:

$$
\operatorname{Ans}(\mathrm{Q})=\lambda \mathrm{w}: \exists \mathrm{p} \in \mathrm{Q}[\operatorname{Exh}(\mathrm{Q}, \mathrm{p}, \mathrm{w})=1] .\{\mathrm{q} \in \mathrm{Q}: \mathrm{w} \in \mathrm{q} \& \mathrm{q} \subseteq(\mathrm{tp} \in \mathrm{Q})[\operatorname{Exh}(\mathrm{Q}, \mathrm{p}, \mathrm{w})=1]]\}
$$

Suppose that in w we can get gas at the first and second locations and nowhere else. We saw in (34)d that the cell-identifiers in the case (21)"a and (21)"b are different: it is the proposition $\measuredangle 1_{1} \wedge \backslash l_{2}$ in the case of (21)"a and $\diamond\left(l_{1} \vee l_{2}\right)$ in the case of (21)"b. Since every true proposition in (21)"a is entailed by $\nabla 1_{1} \wedge \backslash 1_{2}$, the result of applying Ans(w) to (21)"a is a singleton proposition $-\left\{\searrow 1_{1} \wedge \backslash 1_{2}\right\}$. The situation in (21)"b is very different. Applying Ans $(w)$ to this higher-type question yields three propositions $\left\{\searrow\left(1_{1}\right), \diamond\left(1_{2}\right), \diamond\left(1_{1} \vee l_{2}\right)\right\}$. This distinction, I claim, underlies the MS/MA ambiguity. 


\subsection{Existential quantification over the $A n s$-set}

In (21) (repeated below) the responsive predicate know takes a question as complement. I assume that the responsive predicate needs a propositional argument and that this leads to type mismatch: when Ans applies to the question it returns a set of propositions, which is not of the appropriate type.

\section{Mary knows where we can get gas in Cambridge.}

I assume that this type mismatch is resolved when a covert existential quantifier is combined with the interrogative construction and the resulting constituent QRs as in (21)"': ${ }^{38}$

(21)"' $\exists[$ Ans[where we can get gas] $] \lambda$. Mary knows p.

Given the ambiguity of the question where we can get gas, there will be two possible readings for (21). Assume that the actual world belongs to the cell in (34)d. If the embedded question receives the low-type interpretation in (21)"a, the output of Ans would be the singleton $\left\{\searrow 1_{1} \wedge \backslash 1_{2}\right\}$. The sentence would then receive the MA interpretation stating that Mary knows this conjunctive proposition. But if the embedded question receives the high-type interpretation in (21)"b, the output of Ans would be a set of three propositions $\left\{\searrow\left(1_{1}\right), \diamond\left(1_{2}\right)\right.$, $\left.\checkmark\left(l_{1} \vee l_{2}\right)\right\}$, in which case the sentence would assert that Mary knows one of these propositions - the MS reading. ${ }^{39}$ This account can extend to matrix questions if we assume that an addressee can freely choose among members of the Ans set (the output Ans). Or alternatively, we can assume that there are covert performative operators [imperative, cause and know], with the following LF (see, e.g., Hirsch 2017 and Sauerland and Yatsushiro 2017):

\footnotetext{
${ }^{38}$ It is critical to block a representation in which Ans is absent, e.g.: $\exists[$ where we can get gas] $\lambda$ p. Mary knows $p$. One possibility is to assume that the only way to derive a question (without type-mismatch) is by base generating the Ans operator in the argument position of interrogative C (an identity relation among propositions) and QR-ing Ans to its scope position. Thanks to Wataru Uegaki for pressing me on this issue.

${ }^{39}$ This, at the moment, seems too weak. As things stand, the MS reading will be true if Mary just knows the disjunctive cell identifier $\left(\searrow\left(1_{1} \vee l_{2}\right)\right)$ - without knowing that it is a cell-identifier. If Mary knows that in at least one of two locations gas is available, and in fact gas is available in both of the locations, we do not want (21) to come out true, not even on an MS reading. In Fox (2013) I suggested we deal with this by appeal to a stronger notion of Answerhood [leading to the requirement that Mary not just know a member of the Ans-set, p, but also know that $\mathrm{p}$ is a member of the Ans-set, see Heim, 1994 and George, 2011].
}

(i) $\llbracket$ Ans-strong $\rrbracket=\lambda Q . \lambda w\left\{\lambda w^{\prime}\left[p \in \llbracket A n s \rrbracket(Q)\left(w^{\prime}\right)\right]: p \in \llbracket A n s \rrbracket(Q)(w)\right\}$

This suggestion requires a longer discussion than can be had in this context. On the one hand, there might be independent reasons to assume Ans-strong: as pointed out by Spector and Egré 2015, it might be needed for a uniform statement of how responsive predicates take their Q arguments [both veridical and non-veridical]; and, Spector and Egré (2015) have proposed to deal with Heim's original argument against universal use of Ansstrong by claiming that both Ans-strong and Ans-weak are used simultaneously. On the other hand, Klinedinst and Rothschild, 2011 and subsequent work have presented evidence that is problematic for Spector and Egré. I will have to leave this as an open question, but see Spector, 2018 for a defense of Ans-strong in light of counterevidence. There are other possible fixes: with van Rooij (2003) and Schulz and van Rooij (2006), we could add the demand that members of the Ans-set have maximum utility (given a contextually given practical problem). Or we can simply prune all non maximal (i.e. strongest) members from the answer set:

(ii) $\llbracket A n s ' \rrbracket=\lambda \mathrm{Q} \lambda \mathrm{w}: \exists \mathrm{p} \in \mathrm{Q}[\operatorname{Exh}(\mathrm{Q}, \mathrm{p}, \mathrm{w})=1] .\{\mathrm{p}: \mathrm{p} \in \llbracket \mathrm{Ans} \rrbracket(\mathrm{Q})(\mathrm{w}) \& \neg \exists \mathrm{q} \in \llbracket A n s \rrbracket(\mathrm{Q})(\mathrm{w})[\mathrm{q} \subset \mathrm{p}]\}$ 
(36) IMP addressee Cause [ $\exists[$ Ans[where we can get gas] $\lambda$ p. speaker knows $p]$. Make it the case that there is a member of the answer set, $p$, such that I know p.

\subsection{Back to Question Duality}

In this section we have seen that two modifications in $A n s_{D}$ provide an account for MS when coupled with Spector's proposal of higher order quantification. In the next sections, I will try to investigate various predictions made by this account. But first I would like to explain how the modification of $A n s_{D}$ fits into the conception I outlined in sections 1 and 2. The main point is that our restatement of $A n s_{D}$ is based on the idea that answers to a question in a world $\mathrm{w}$ are defined based on the proposition that identifies the cell to which $\mathrm{w}$ belongs (in the partition induced by the question). When this proposition is weaker than other members of the Hamblin set, we get MS; when it is the maximally informative true member, we get MA. Though the method of cell identification is different from that assumed by Dayal, we share with her a presupposition that guarantees $\mathrm{CI}$.

In fact it would once again be equivalent to CI. And, as before, CI can be stated directly allowing us to accommodate the proposal in section 3. Specifically, Ans as defined in (35) could be restated as an operator that takes an information state, I, (the context set with veridical predicates) and a world, w, and demands that QPM be met. ${ }^{40}$

$$
\begin{aligned}
& \operatorname{Ans}(\mathrm{Q})=\lambda \mathrm{I}: \mathrm{QPM}(\mathrm{Q}, \mathrm{I}) . \lambda \mathrm{w} .\{\mathrm{q} \in \mathrm{Q}: \mathrm{w} \in \mathrm{q} \& \mathrm{q} \subseteq(\mathrm{tp} \in \mathrm{Q})[\operatorname{Exh}(\mathrm{Q}, \mathrm{p}, \mathrm{w})=1]]\} \\
& \text { where }(\mathrm{QPM}(\mathrm{Q}, \mathrm{I}) \text { holds iff } \\
& \text { a. } \quad \mathrm{CI}: \forall \mathrm{C} \in \operatorname{Partition}_{\mathrm{C}}(\mathrm{Q}, \mathrm{A}) \exists \mathrm{p} \in \mathrm{Q}\left([\operatorname{Exh}(Q, p)]_{\mathrm{A}}=\mathrm{C}\right) \text { and } \\
& \text { b. } \quad \mathrm{NV}: \forall \mathrm{p} \in \mathrm{Q} \exists C \in \operatorname{Partition}_{\mathrm{C}}(\mathrm{Q}, \mathrm{A})\left([\operatorname{Exh}(Q, p)]_{\mathrm{A}}=\mathrm{C}\right)
\end{aligned}
$$

Or equivalently, as pointed out to me by Roger Schwartzchild, we can dispense with Partition $_{\mathrm{C}}$ and assume that partitions are derived by point-wise exhaustification:

$$
\begin{aligned}
& \text { Ans }(\mathrm{Q})=\lambda \mathrm{I}: \operatorname{Partition}(\mathrm{Q}, \mathrm{I}) . \lambda \mathrm{w} .\{\mathrm{q} \in \mathrm{Q}: \mathrm{w} \in \mathrm{q} \& \& \mathrm{q} \subseteq(\mathrm{tp} \in \mathrm{Q})[\operatorname{Exh}(\mathrm{Q}, \mathrm{p}, \mathrm{w})=1]]\} \\
& \text { where }(\operatorname{Partition}(\mathrm{Q}, \mathrm{I}) \text { holds iff point wise exhausfication of } \mathrm{Q} \text { is a partition of } \mathrm{I} \text {. } \\
& \text { I.e., iff }\left\{\left[\operatorname{Exh}_{\mathrm{Q}}(\mathrm{p})\right]_{\mathrm{I}}: \mathrm{p} \in \mathrm{Q}\right\} \text { partitions } \mathrm{I} \text {. }
\end{aligned}
$$

\section{Is an existential quantifier necessary?}

Under the proposal made in section 4, MS is only possible when the cell identifier for Q is weaker than other true propositions in $\mathrm{Q}$, which is, in turn, only possible when an existential operators c-command the trace of $w h$-movement. ${ }^{41}$ Is this particular consequence correct? At first sight, it might seem to be, as the required operator is present in canonical examples of MS, such as (21). However, the empirical picture is far from clear. While various authors have argued that existential operators are required for MS (Chierchia and Caponigro, 2013; George, 2011 chapter 6; Fox, 2013; Xiang 2016), others have claimed that the governing factor pertains to pragmatic considerations to which we return in section 7 (Groenendijk and

\footnotetext{
${ }^{40}$ To deal with non-veridical predicates, we can assume with Spector and Egré (2015) that there is existential quantification over I and w, which will require a stronger notion of answerhood. See note 39.

${ }^{41}$ This is the FC environment - where Q is closed under conjunction but not under disjunction.
} 
Stokhof, 1984; Schulz and van Rooij, 2006; van Rooij, 2003, 2017). See Dayal, 2016 for some discussion.

Consider the questions in (39) and (40), all of which can receive an MS interpretation. The two questions in (39), like (21), both have an existential operator in the required position. But this is not obviously the case for the questions in (40).

(39) a. Where can I buy an Italian newspaper?

b. How can I get to the Station?

(van Rooij, 2017)

(40) a. Who has a light?

b. Who, for example, supported the bill?

(van Rooij, 2017)

(Beck and Rullmann, 2009)

Nevertheless, it might be possible to argue that an existential operator is present in an appropriate position, despite initial appearances: in (40)a the verb has (which shows a definiteness effect) has been famously analyzed as involving existential quantification (Freeze, 1992), and in (40)b the phrase for example, can be analyzed as an existential quantifier. (Consider John is an example of a senator that supported the bill). Such analyses would not be implausible, as all of the questions show the FC effect: in all of them a disjunctive answer can be understood conjunctively, the crucial ingredient for MS, under the account advocated here: ${ }^{42}$

(41) a. Where can I buy an Italian newspaper?

Either at store A or at store B.

b. How can I get to the Station?

Either by following John or by following Mary.

(42) a. Who has a light?

Either John or Mary

b. Who, for example, supported this bill?

?McCain or Kennedy (are examples of senators who supported the Bill)

However, there are cases of MS where existential quantification is clearly absent. Consider the following examples suggested to me by Floris Roelofson:

(43) a. Who is going to the party (by car)?

b. Mary knows who is going to the party.

When the appropriate pragmatic conditions are met, e.g. when people are trying to figure out how to get to a party, the questions in (43) can receive an MS interpretation. And here no

\footnotetext{
${ }^{42}$ The judgment in the case of (42)b is less clear to me than in the other examples. Still I think that a conjunctive interpretation is possible, as is perhaps clearer the following:

i. $\quad$ McCain OR Kennedy. They are the best examples I can think of.

ii. Either McCain or Kennedy is a good example.

In any event there will be clear cases where MS is present without existential quantification, so, at the end of the day, it might not be so important to figure out what happens in this particular case.
} 
existential operator c-commands the trace and I don't think a disjunctive fragment answer can be interpreted conjunctively. This looks like a problem.

What I would like to suggest is that the MS interpretation in this case has a different explanation. The question, I suggest, receives an MA interpretation with covert domain restriction. Such domain restriction can lead to an MS illusion, as in Schwarzschild's (2000) analysis of the scope illusion that arises when existentials are embedded inside an island singleton indefinites (see discussion in von Fintel, 2000). For example, the question in (43) might be interpreted as a request to specify all of the people going to the party whose plans the addressee is aware of (who among the people whose plans for the party you know is going?). ${ }^{43}$

While I am not in a position to develop a full argument here, I think that the contrast in (44) might be taken to support this line of approach.

(44) a. Everyone here knows where we/one can get gas.

b. $\quad$ Everyone here knows how we/one can get to the party.

c. Everyone here knows who is going to the party.

The (a) and (b) sentences in (44) can receive an MS interpretation consistent with everyone knowing a different answer to the question: everyone here knows some place - potentially a different place - where we can get gas (or a different way of getting to the party). This is not the case, I think, for the sentence in (44)c. If this sentence receives an MS interpretation at all, it involves what we might call uniform MS, where what everyone knows is the same thing. ${ }^{44}$ This contrast would follow if the route to MS in (44)c involves domain restriction and if it is somewhat difficult in this case to come up with a domain restrictor that includes a variable bound by the matrix subject. ${ }^{45}$ If this is correct, we might be able to conclude that MS requires an existential operator c-commanding the trace of wh-movement.

To see if this line of reasoning is correct, it would be very useful to find ways of controlling for domain restriction. Since I don't quite know how to do this, all I can offer in support of my conjecture at this stage are minimal pairs such as those in (44) [and the corresponding contrast in note 44], hoping that their account is based on difficulties associated with the complexity of the necessary domain restriction. Here's another minimal pair. ${ }^{46}$ Suppose that there was no gas in the greater Boston area for a couple of days (say... the aftermath of a

\footnotetext{
${ }^{43}$ If $w h$ Ps are existential quantifiers (as in Karttunen, 1977), we should expect to find similar illusive domain restriction to arise here. Specor (2018) claims that weak-exhaustivity is also an illusion arising from domain restriction.

${ }^{44}$ Here is a similar contrast which supports the same conclusion. Suppose you find two people arguing about where to go get gas. (i) sounds like a natural way to stop the argument. But (ii) would not be a reasonable way to break the analogous argument about who to take a ride with (as apposed to (iii) which again contains a modal).

(i) Why are you arguing? You actually both know where one can get gas.

(ii) \#Why are you arguing? You actually both know who is going to the party.

(iii) Why are you arguing? You actually both know how one can get to the party.

${ }^{45}$ Thanks to Irene Heim for help in thinking through this example.

${ }^{46}$ This is an example from Fox, 2013 inspired by the discussion in George, 2011.
} 
storm). Suppose Josh got a huge tank truck and delivered gas to various gas stations (so that people like us can get gas).

When I asked people to imagine that all of this is part of the common ground, they reported different judgments for the questions in (45). These questions, in such a context, should be asking for exactly the same information, as it is contextually given that the places where one can get gas are precisely those places where Josh delivered gas. ${ }^{47}$ Nevertheless, MS is harder to get in (45)b. The contrast is stronger, I think, in (46) if we focus on situations where everyone knows different MS answers (differential MS). If, for some reason, the necessary implicit domain restriction is even more difficult in these cases, the contrast would follow from the proposal made in this paper.

(45) a. Mary knows where we can get gas.

b. Mary knows where Josh delivered gas.

(MS, MA)

(?MS, MA)

(46) a. Luckily everyone knows where one can get gas.

(MS, MA)

b. $\quad$ Luckily everyone knows where Josh delivered gas. (*MS, MA)

\section{Constraints on higher types}

To get MS, under the proposal made here, wh-movement must cross an existential quantifier. But this is not a sufficient condition. It is also necessary for a trace in the scope of the existential quantifier to be interpreted as a higher-type variable (ranging over GQs). If there are environments where such an interpretation is not available, we expect MS to be unavailable as well.

\subsection{Singular wh phrases}

(47) and (48) below contrast in the availability of the interpretation identified by Spector.

a. What are you required to read for this class?

War and Peace or Brothers Karamazov. $\quad$ (Required $>$ or; or $>$ required)

b. Which books are you required to read for this class?

The Russian books or the French books. (Required $>$ or; or $>$ required)

(48) Which book are you required to read for this class?

War and Peace or Brothers Karamazov.

$(*$ Required $>$ or; or $>$ required $)$

This contrast can be taken to argue that singular wh-phrases cannot quantify over higher-type traces. Why this should be the case is not critical for current purposes. What is important is that it leads to an expectation in the domain of MS. Specifically, we expect MS to be absent for singular whPs (as long as we can control for domain restriction).

\footnotetext{
${ }^{47}$ Floris Roelofson (p.c.) notes that although the two questions are contextually equivalent, the difference in their form might make different practical problems salient. I do not know how to deal with this confound.
} 
Suppose that a department chair, Sue, is required to form a committee with three professors as members, one of them serving as chair. To meet the pragmatic conditions (which we will be touching on in the next section) assume that Sue thinks the committee is not particularly important and that she would be willing to appoint anyone who is available to serve. In such a context, (49)a can receive an MS reading and (49)b cannot, or at least not easily (a contrast which is perhaps sharper if we insist on differential MS in (50), as in (44) and (46) and the examples in note 44$)$.

(49) a. Sue knows who can serve on this committee.

(MS, MA)

b. Sue knows which professor can chair this committee. (?MS, uniqueness)

a. (Why are you arguing?) You both know who can serve on this committee.

(Differential MS possible for some speakers)

b. (Why are you arguing?) You both know which professor can chair this committee. (Differential MS impossible)

If these contrasts are real, they can serve to argue that higher order quantification is necessary for true MS, as predicted by our proposal (with illusory MS slipping in by domain restriction, e.g. which professor that she asked...).

The argument would of course be better understood if we could explain the constraint on higher-order quantification. While I cannot do much here, I can provide further reasons to believe that the constraint is real. ${ }^{48}$ Consider the sentences in (51) and imagine that there is no particular book that Sue is required to read. Under such circumstances, the sentences would be unacceptable as expected given the existence presupposition of the definite article. What is important for my purposes is that this holds even if there is a disjunctive reading requirements, e.g. if Sue is required to read one of two books (of her own choice), say either $\mathrm{W} \& \mathrm{P}$ or $\mathrm{BK}$.

(51) a. Mary is required to read the book Sue is.

b. The book that Sue is required to read can be read in one week. Deviant if Sue is required to read [W\&P or BK] (required $>$ or) and nothing else.

Now consider the sentences in (52) and (53). These sentences are no longer deviant when only a disjunctive requirement holds, something that is mysterious if the trace of $w h$ movement is interpreted as a variable ranging over individuals - given the existence presupposition associated with free relatives and plural definite descriptions. However, it is explained if the variables can range over GQs with the disjunction satisfying the presupposition (see von Fintel, Fox and Iatridou, 2014 to understand how a maximality presupposition would be satisfied).

\footnotetext{
${ }^{48}$ One possibility is that the mechanism that allows for higher order quantification, the necessary type shift rule, $\mathrm{S}$ (or the morpheme that converts the restrictor of the $w h \mathrm{P}$ ), takes a predicate $\mathrm{A}$ of individuals and forms a predicate of GQs, based on the plural individuals in A (as in Cand $_{x}$ from Križ and Spector, 2017, ex. (30)):
}

$(1) \llbracket \mathrm{S} \rrbracket(\mathrm{A})=\lambda \mathrm{Q} . \exists \mathrm{x} \in \mathrm{A} \& \exists \mathrm{A}^{\prime}\left(\mathrm{A}^{\prime} \subseteq\left\{\mathrm{x}^{\prime}: \mathrm{x}^{\prime} \leq \mathrm{x}\right\} \& \mathrm{Q}=\lambda \mathrm{P} . \exists \mathrm{x}\left[\mathrm{A}^{\prime} \cap \mathrm{P} \neq \varnothing\right]\right)$ 
(52) a. Mary is required to read what Sue is.

b. What Sue is required to read can be read in one week.

(53) a. Mary is required to read the books Sue is.

Suppose that Sue is required to read [W\&P and BK] or [MB and SE] (required $>$ or) and nothing else. The sentence need not be a presupposition failure and will entail that the same requirements were made of Mary.

b. The books that Sue is required to read can be read in one week.

Suppose that Sue is required to read [W\&P and $B K]$ or [MB and SE] (required $>$ or) and nothing else. The sentence need not be a presupposition failure and will entail that each pair of books that can satisfy the requirements can be read in one week.

The contrast can be explained if higher order quantification is impossible when variables (prior to type shift) range over singular individuals. And this constraint, in turn, leads to the prediction for MS stated in (49).

\subsection{Floating quantifiers}

Consider the following example from Križ, 2015, p. 192.
Nina weiß, wo man überall Käse kaufen kann.
Nina knows where one everywhere cheese buy can
'Nina knows all the places where we can get cheese.'

Križ points out that MS is impossible in this example and that this impossibility is to be attributed to the expression überall. (If the expression is removed, MS is possible.) His explanation is based on a property that he attributes to expressions such as überall and all which he calls homogeneity removal. I would like to point out that the approach developed here provides an alternative that relies only on the semantic type of überall: on the assumption that it has a semantic type analogous to that of all. All is analyzed as an expression that combines with a plural individual and returns a generalized quantifier (or alternatively combines with a predicate of individuals and returns another predicate of individuals). By analogy, überall will combine with a plural location (the trace of the whphrase wo in (54)) and return a generalized quantifier over locations. ${ }^{49}$ From this, it follows that the trace of wo must range over locations and not generalized quantifiers, and this, in turn, predicts absence of MS (under the approach developed here).

But an additional prediction is made, namely that überall can be introduced in a lower position in successive cyclic wh-movement while still allowing for MS. The crucial observation is that the trace in the base position in Spector's representation of the higher-type meaning can be interpreted as a low-type variable (one that can appear in an argument position). In (22)', for example, it is only an intermediate trace (Q) that is interpreted as a higher type variable, whereas the lower trace $\mathrm{x}$ is interpreted as variable of a lowest type.

\footnotetext{
${ }^{49}$ See Heim, Lasnik and May 1991. Of course things will not change if überall combined with a predicate of locations and returned a new predicate of locations.
} 
(22)' Higher-Order Quantification:

LF: Wh shift(restrictor) $\lambda \mathrm{Q}_{\text {ett }} \mathrm{we}_{1}$ are required $\mathrm{Q} \lambda \mathrm{x}$. $\mathrm{PRO}_{1}$ to read $\mathrm{x}$ for this class?

We thus predict MS to be distributed in the following examples as indicated, a prediction that corresponds to the judgments of a few speakers of "Austrian German" with whom I've consulted. ${ }^{50}$

Was kann ich alles zusammenmischen sodass es eine Explosion gibt?

What can I all together-mix so-that there an explosion is

MS possible

(56) a. Was kann ich alles tun sodass ich eine gute Note kriege?

MS possible

What can I all do so-that I a good grade get

b. Was alles kann ich tun sodass ich eine gute Note kriege?

What all can I do so-that I a good grade get

a. Was kann ich alles mit 3 Euros kaufen?

only MA

What can I all with 3 Euros buy

b. Was alles kann ich mit 3 Euros kaufen?

MS possible

What alles can I with 3 Euros buy

only MA

\section{Pragmatic constraints on MS}

Under the proposal made in this paper, two formal conditions must be met for MS to be possible: (a) an existential operator must intervene between a wh operator and one of its traces and (b) a trace in the scope of the existential operator must receive a higher-type interpretation (range over GQs). In sections 5 and 6, I tried to investigate these constraints focusing on environments where they are not met. While the availability of implicit domain restrictions makes it difficult to reach firm conclusions, I think that we have seen a few contrasts that can be taken to support the general outlook.

However, it is well known that MS is constrained by pragmatic factors (Groenendijk and Stokhof, 1994; van Rooij, 2004; van Rooij and Schultz, 2006). My hope, following George, 2011 (section 6.1.2), is that the relevant pragmatic factors can be thought of as considerations that enter into disambiguation. For example, following van Rooij, we might claim that a question must have a useful function in guiding action and that the MS interpretation cannot serve this function unless the relevant pragmatic conditions are met. While this line of thought needs to be worked out, I think there are good reasons to think that the pragmatic considerations entertained in the literature are not sufficient to constrain MS, and that formal conditions are needed as well. In addition to the considerations discussed in sections 5 and 6 (and to George, 2011, section 6.1.2), I would like to mention an important argument made in Xiang, 2016.

Xiang points out that if the pragmatic conditions discussed in the literature were taken to be sufficient we would incorrectly predict the existence of what she calls "mention n readings".

${ }^{50}$ Thanks to Martin Hackl, Patrick Grosz and Manuel Križ for consultation. 
The conditions allow MS whenever there is a salient practical problem that would be resolved with (what would otherwise be) a partial answer to a question. So if we need to fill the car with gas, knowing one convenient place where one can get gas would be sufficient. Hence Mary knows where one can get gas? can be paraphrased as the statement that she knows one location where gas is available. But if the pragmatic conditions were sufficient, we would expect other practical problems to lead to very different demands from a partial answer leading to novel interpretations that have not been reported in the literature.

Suppose there was a practical problem that could only be resolved if we knew two places where we could get gas. If the pragmatic accounts were right, an answer to a question such as where can one get gas? what gas stations are open? etc. would need to specify two and no more than two locations. Assume, for example, that I am told I would be executed unless I can mention two locations where one can get gas. The practical problem (avoiding execution) cannot be resolved by a standard MS answer to the question, and if the pragmatic conditions have to be met, this should disfavor a standard MS reading. But if the pragmatic approaches were correct, we should expect to find a mention-two reading, which we don't.

(58), for example, is a sensible thing to utter if the speaker thought Mary knew an MA answer to the question. MS would be insufficient because the practical problem is not resolved and this can be taken to argue that the pragmatic constraints are indeed active. But what is important for Xiang's argument is the prediction made by the pragmatic accounts, namely, that in this context the sentence would receive an interpretation that can be paraphrased with the statement that Mary knows two locations where one can get gas, (58)a, or two gas stations that are open, (58)b, and this does not seem to be the case.

(58) What you just told me - this threat of an execution - is of course disturbing. But I'm not worried, I can ask Mary:

a. She knows where one can gas.

b. She know what gas stations are open. ${ }^{51}$

In fact, the pragmatic accounts predict many other types of mention-x readings that I do not think are available. Suppose Mary is missing one professor for a committee (and that anyone would do). If she knew of one available professor, it would be true to say that she knows who can serve on the committee (on the MS reading). Suppose, however, that her practical problem does not require that much knowledge. Suppose that all she needs to know is a department that has a professor available in it, so that she can call and have the professor sent over. Suppose further that she has this information available - the math dept. has a few available Profs. I think that the first two sentences in (59) will be true but (59)c will be false.

(59) a. Mary knows who can send her a professor.

b Mary knows what kind of professor can serve on the committee. (A math professor.)

c. Mary knows which professor can serve on this committee. (A math professor.)

\footnotetext{
${ }^{51}$ Although the judgment seems rather clear to me, we expect the facts (here and in (59)) to be contaminated by implicit domain restriction (and to become sharper when we introduce quantifiers and consider differential mention $\mathrm{x}$ ).
} 
As far as I can tell, the pragmatic accounts predict that (59)c should get a mentiondepartment reading. Specifically, the partial answer to the question specifying that a professor from the math department is available resolves the salient practical problem of knowing who to call.

What Xiang's example teaches us is that there is no mention- $n$ interpretation. What (59) teaches us is that there is no mention-department interpretation. There is a very specific MS interpretation, which can be accessed only if certain pragmatic conditions are met. But these conditions are not sufficient. There are formal conditions as well which I hope to have helped elucidate.

\section{Conclusions}

MS is not compatible with Dayal's notion of an answer. To deal with this problem, I offered a new Answer operator in section 4, which differs from $A n s_{D}$ in two different ways. First instead of demanding that the question denotation, Q, have a maximally informative true member, Ans demands that $\mathrm{Q}$ have a member that can identify the cell in the partition to which the actual world belongs (that $\mathrm{Q}$ have a cell-identifier). And second, since the cellidentifier need not be the strongest true proposition in Q, we let the output of Ans be the set of true propositions that entail the cell identifier. MS arises whenever the output of Ans has more than one member. There are various empirical consequences to this account of MS that I investigated in sections 5-7.

The demand for cell identification makes it natural to ask whether the converse demand holds as well, namely the demand for NV: not only should every cell be identifiable by a member of Q, but also every member of Q must identify a cell. NV was supported in section 3, leading to the final proposal in (37), which could be restated (as pointed out by Schwarzschild) as the demand that point wise exhaustification provide us with the necessary partition - (38). Either way, we resolve the problem of question duality that was introduced in the sections 1-2.

\section{References}

Abrusán, M. (2007). Contradiction and grammar: the case of weak islands. PhD thesis. MIT. Abrusán, M. (2014). Weak Island Semantics. Oxford University Press.

Abrusán, Márta \& Benjamin Spector. (2011). An interval-based semantics for degree questions: negative islands and their obviation. Journal of Semantics. 28(1). 107-147.

Alonso-Ovalle, L. (2006). Disjunction in Alternative Semantics. Ph.D. thesis. University of Massachusetts, Amherst.

Aravind, A. and M. Hackl (2017). Against a unified treatment of obligatory presupposition triggers. Proceedings of SALT 27.

Bade, N. (2016). Obligatory presupposition triggers in discourse - empirical foundations of the theories maximize presupposition and obligatory implicatures. Tübingen: Universität Tübingen $\mathrm{PhD}$ dissertation. 
Bar-Lev, M. E. (2018). Free Choice, Homogeneity, and Innocent Inclusion. PhD thesis in progress. Hebrew University of Jerusalem.

Bar-Lev, M.E. and D. Fox (2017). Universal Free Choice and Innocent Inclusion. In D. Burgdorf, J. Collard, S. Maspong, and B. Stefánsdóttir (Eds.), Proceedings of the 27th Semantics and Linguistic Theory Conference, held at the University of Maryland, College Park May 12-14, 2017, pp. 95-115.

Bar-Lev, M.E. and D. Fox (2018). Simplification by Inclusion. Talk Presented at LingLunch, MIT.

Bylinina, L. and Nouwen, R. (to appear). On "zero" and semantic plurality, to appear in Glossa.

Chierchia, G. (2013). Logic in Grammar: Polarity, Free Choice, and Intervention. Oxford University Press.

Chierchia G. and I. Caponigro (2013). Questions on questions and free relatives. Talk presented at Sinn und Bedeutung 18. https://scholar.harvard.edu/files/chierchia/files/frs and qs iii 2013-9-11.pdf

Cremers, A. and E. Chemla. (2016). A psycholinguistic study of the exhaus-tive readings of embedded questions. Journal of Semantics 33:49-85.

Crnič, L., E. Chemla and D. Fox (2015). Scalar Implicatures of Embedded Disjunction. Natural Language Semantics, 23(4): 271-305.

Crnič, L. (2016). Free Choice under Ellipsis. The Linguistic Review, 34(2). pp. 249-294

Dayal, V. (1996). Locality in WH Quantification: Questions and Relative Clauses in Hindi, Studies in Linguistics and Philosophy. Kluwer Academic Publishers.

Dayal, V. (2016). Questions. Oxford University Press.

Elliott, P. D., Nicolae, A. C., and Sauerland, U. (2017). Who and what do who and what range over cross-linguistically?. Paper presented at Theoretical and experimental approaches to presuppositions, Genoa, Italy.

von Fintel, K. (2000). Singleton Indefinites (re. Schwarzschild 2000). Paper presented in the Syntax-Semantics Reading Group, MIT. http://web.mit.edu/fintel/fintel-2000singleton.pdf

von Fintel, K., D. Fox and S. Iatridou. (2014). Definiteness as maximal informativeness. In L. Crnič and U. Sauerland (Eds.), The Art and Craft of Semantics: A Festschrift for Irene Heim, , 165-174. Cambridge MA: MITWPL 70.

Fox, D. (2000). Economy and Semantic Interpretation. MIT Press.

Fox D. (2007). Free choice disjunction and the theory of scalar implicatures. In Sauerland U. Stateva P. (Eds.), Presupposition and Implicature in Compositional Semantics. Palgrave Macmillan. London. 71-120.

Fox, D. (2007). Too many alternatives: Density, symmetry and other predicaments. In Proceedings of SALT 17, 89-111. Ithaca, N.Y.: CLC Publications.

Fox. D. (2010). Negative Islands and Maximization Failure, Paper presented at MIT linguistic colloquium. http://lingphil.mit.edu/papers/fox/MIT_Colloq 2010.pdf.

Fox, D. (2013) Mention-some readings of questions, class notes, MIT seminars. http://lingphil.mit.edu/papers/fox/class1-3.pdf.

Fox, D. \& M. Hackl. (2006). The universal density of measurement. Lingustics and Philosophy 29(5). 537-586.

Fox D. and R. Katzir (2011). On the characterization of alternatives. Natural Language Semantics. 19. 87-107

Freeze, Ray. (1992). Existentials and other locatives. Language 68. 553-595. 
George, B. R. (2011). Question embedding and the semantics of answers. $\mathrm{PhD}$ thesis. University of California, Los Angeles.

Groenendijk, J. and Stokhof, M. (1984). Studies on the Semantics of Questions and the Pragmatics of Answers. Ph.D. thesis. University of Amsterdam.

Guerzoni, E. (2003). Why even ask?: on the pragmatics of questions and the semantics of answers, PhD thesis. MIT.

Guerzoni, E. and Y. Sharvit. (2007). A question of strength: on NPIs in interrogative clauses. Linguistics and Philosophy 30:361-391.

Guerzoni, E. and Y. Sharvit. (2014). Whether or not anything but not whether anything or not. In The Art and Craft of Semantics: a Festschrift for Irene Heim, L. Crnič and U. Sauerland (Eds.), 199-224. Cambride, MA: MIT Working Papers in Linguistics (MITWPL).

Hirsch. A. (2017). An inflexible semantics for cross-categorial operators. PhD thesis. MIT.

Hagstrom, P. (2003). What questions mean. Glot International 7(7/8): 188-201.

Hamblin, C. L. (1958). Questions. Australasian Journal of Philosophy, 36, 159-16

Hamblin, C. L. (1973). "Questions in Montague English," Foundations of Language 10, 4153. Reprinted (1976). in B. Partee (ed.) Montague Grammar. New York: Academic Press, 247-259.

Heim, Irene. (1994). Interrogative semantics and Karttunen's semantics for know. In Proceedings of the Ninth Annual Conference of the Israeli Association for Theoretical Linguistics and the Workshop on Discourse. Rhona Buchalla \& Anita Mitwoch (Eds.), volume 1, 128-144.

Karttunen, Lauri. (1977). Syntax and semantics of questions. Linguistics and Philosophy 1:344.

Katzir, R. (2014). On the roles of markedness and contradiction in the use of alternatives. In Reda, S. P., editor, Pragmatics, Semantics and the Case of Scalar Implicatures, pages 40 71. Palgrave Macmillan UK, London.

Kratzer, A. and J. Shimoyama. (2002). Indeterminate pronouns: The view from Japanese. In Yukio Otsu (ed.), Proceedings of the Tokyo conference on psycholinguistics.

Krifka, M. (1995). The semantics and pragmatics of polarity items. Linguistic Analysis 25: 209-257

Klinedinst, N. and D. Rothschild. (2011). Exhaustivity in questions with non-factives. Semantics and Pragmatics 4:1-23.

Lahiri, U. (2002). Questions and Answers in Embedded Contexts. Oxford University Press, 2002.

Magri, G. (2009). A theory of individual-level predicates based on blind mandatory scalar implicatures. Natural Language Semantics 17(3). 245-297.

Magri, G. (2011). Another argument for embedded scalar implicatures based on oddness in downward entailing contexts, Semantics and Pragmatics. 4.6. 1-51.

Nicolae, A. (2013). Any questions?: Polarity as a window into the structure of questions. Harvard University Ph. D

Oshima, D. Y. (2007). On Factive Islands: pragmatic anomaly vs. pragmatic infelicity. In New Frontiers in Artificial Intelligence, 147-161. Springer.

Reinhart, T. (1983). Anaphora and Semantic Interpretation. Chicago: University of Chicago Press.

van Rooij. R. (2004). The utility of mention-some questions. Research on Language and Computation. 2:401-416. 
Rooth, M. (1992). A theory of focus interpretation. Natural Language Semantics 1(1). 75116.

Romero, M. (1998). Focus and reconstruction effects in wh-phrases. Ph.D. thesis, University of Massachusetts, Amherst.

Sauerland, U. and K. Yatsushiro. (2017). Remind-Me Presuppositions and Speech-Act Decomposition: Evidence from Particles in Questions. Linguistic Inquiry.

Schulz, K. and R. van Rooij. 2006. Pragmatic meaning and non-monotonic reasoning: The case of exhaustive interpretation. Linguistics and Philosophy, 29(2):205-250.

Schwarzschild, R. (2002) Singleton Indefinites. Journal of Semantics, 19, 3, 1 August 289314.

Schwarz, B. and J. Shimoyama. (2011). Negative islands and obviation by wa in Japanese degree questions. Semantics and Linguistic Theory 20. 702-719.

Schwarz, B. and A. Simonenko. (2016). Two accounts of factive islands. in Brandon Prickett and Christopher Hammerly (eds.), Proceedings of 46th Meeting of the North East Linguistic Society (NELS 46), Vol. 3, pp. 169-178. GLSA, University of Massachusetts, Amherst.

Singh, R., K. Wexler, A. Astle-Rahim, D. Kamawar and D. Fox. (2016). Children interpret disjunction as conjunction: Consequences for theories of implicature and child development. Natural Language Semantics 24(4). 305-352.

Spector, B. and P. Egré. (2015). A uniform semantics for embedded interrogatives: An answer, not necessarily the answer. Synthese 192:1729-1784.

Spector, B. (2018). Revisiting Weak Exhaustivity. Talk presented at MiQ, Konstanz.

Uegaki, W. (2015). Interpreting questions under attitudes. Doctoral dissertation, Massachusetts Institute of Technology, Cambridge, Massachusetts. URL https: //dspace.mit.edu/handle/1721.1/99318.

Xiang, Y. (2016). Interpreting Questions with Non-Exhaustive Answers. PhD thesis. Harvard University. 